\title{
Pouancé (Maine-et-Loire), ou la constitution d'une ville castrale entre Bretagne et Anjou, du XIe au XIXe siècle
}

Pouancé or the constitution of a castle town between Brittany and Anjou from the eleventh to the nineteenth century

Jean-Claude Meuret et André Neau

\section{(2) OpenEdition}

\section{Journals}

\section{Édition électronique}

URL : http://journals.openedition.org/abpo/2383

DOI : $10.4000 / a b p o .2383$

ISBN : 978-2-7535-2129-2

ISSN : 2108-6443

\section{Éditeur}

Presses universitaires de Rennes

\section{Édition imprimée}

Date de publication : 30 juin 2012

Pagination : 7-54

ISBN : 978-2-7535-2127-8

ISSN : 0399-0826

Référence électronique

Jean-Claude Meuret et André Neau, «Pouancé (Maine-et-Loire), ou la constitution d'une ville castrale entre Bretagne et Anjou, du XIe au XIXe siècle », Annales de Bretagne et des Pays de l'Ouest [En ligne], 119-2 | 2012, mis en ligne le 30 juin 2014, consulté le 02 mai 2019. URL : http:// journals.openedition.org/abpo/2383; DOI : 10.4000/abpo.2383 


\title{
Pouancé(M aine-et-Loire), ou la constitution d'une ville castrale entre Bretagne et Anjou, du XI ${ }^{\mathrm{e}}$ au XIX ${ }^{\mathrm{e}}$ siècle
}

\author{
Jean-Claude MEURET \\ Maître de conférences en archéologie \\ André NEAU \\ Professeurd esé coles
}

\begin{abstract}
Le phénomène de l'urbanisation médiévale intéresse depuis longtemps historiens et archéologues ${ }^{1}$. Par ailleurs, les villes de la marche bretonne, jusque-là perçues comme périphériques, se trouvent aujourd'hui au centre de divers projets culturels ou touristiques ${ }^{2}$. Parmi elles, Pouancé tient une place particulière. D'abord, pour des raisons historiques : à partir du début du XII ${ }^{\mathrm{e}}$ siècle, elle fut le siège d'une seigneurie double, mi-angevine puis française, et mi-bretonne; plus tard, à la fin du Xve siècle, elle servit de base militaire aux armées royales, lors de l'attaque de la Bretagne. Et puis pour des raisons archéologiques : la ville de Pouancé ne s'est en effet guère développée après le Moyen Âge. Ainsi, conserve-t-elle, plus ou moins figées, des traces parfois archaïques de son organisation médiévale qui ne subsistent plus dans des villes ayant connu un fort développement postérieur. C'est la conjonction de deux approches d'abord distinctes, d'une part la collecte des sources écrites archivistiques, et d'autre part la lecture archéologique appuyée sur les sources médiévales, qui nous a amenés à traiter en commun le dossier de la constitution de la ville de Pouancé. La perspective choisie est celle du temps long, $\mathrm{du} \mathrm{XI}^{\mathrm{e}}$ au XVI ${ }^{\mathrm{e}}$ siècle et même au XIX ${ }^{\mathrm{e}}$ siècle. Elle seule, peut permettre d'analyser le processus de création de la ville en faisant le distinguo entre ce qui relève des actions humaines et politiques
\end{abstract}

1. Dans ce vaste champ de recherche, une des approches les plus récentes et novatrices : NoIzET, Hélène, La Fabrique de la ville. Espaces et sociétés à Tours (IXe-XIII siècle), 2007, Publications de la Sorbonne, 504 p.

2. En particulier la préparation de la candidature des villes de la marche bretonne pour un classement au Patrimoine mondial de l'UNESCO. 
volontaires, immédiates, et ce qui appartient à l'impensé et à la durée, à ce qu'on nomme à présent " la fabrique de la ville ".

\section{Historique de la recherche, bibliographie, méthodologie}

La recherche archéologique sur le château de Pouancé entamée par le CHAM (Chantiers Histoire et Architecture médiévales) sous l'impulsion de Louis Bessière dans les années 1980, poursuivie par les opérations de l'AFAN (Association pour les fouilles archéologiques nationales) que dirigea Thierry Géhant jusqu'au début des années 1990, n'a en rien concerné l'enceinte urbaine de la ville de Pouancé. Observateur attentif et éclairé du Pouancé ancien, Louis Bessière a cependant donné plusieurs articles dans la presse locale où il décrit de brèves mises au jour de murs ou fossés faites à l'occasion de travaux urbains. D'autre part, depuis plusieurs années, une étude du château est entamée ${ }^{3}$. Aussi, cet article portera-t-il avant tout sur la ville et ses faubourgs, depuis le $\mathrm{XI}^{\mathrm{e}}$ siècle, jusqu'à aujourd'hui.

Aucune étude archivistique spécifique ou de terrain n'a été consacrée au sujet ni publiée. Quelques monographies anciennes ont porté sur Pouancé, telles celles du Marquis de Preaulx ${ }^{4}$ en 1832 et de H. Godivier ${ }^{5}$ en 1906, centrées sur l'histoire seigneuriale traditionnelle, accessoirement sur le château et son histoire, mais peu sur la ville proprement dite. Seule publication spécifique pour l'instant, mais partielle, le chapitre et les annotations que l'un de nous a consacrés aux débuts de cette ville dans les actes du colloque "Villes castrales " de Vitré, en 2007 et publié en 2010 aux PUR; mais seulement à l'intérieur d'une étude plus large portant sur les origines et les débuts des villes de la marche bretonne ${ }^{6}$. Dans cette publication, les sources textuelles utilisées sont essentiellement médiévales, pour la plupart inédites et conservées aux Archives départementales d'Angers. Elles ont sans cesse été confrontées aux données de terrain encore visibles, à l'occasion de nombreuses visites de jardins, murs, fossés et caves ${ }^{7}$. Depuis, ces visites in situ ont continué, permettant les observations d'appareil, les dénivellations, les photographies, les relevés pierre à pierre, la réalisation de planches. C'est ainsi qu'ont été faites de réelles découvertes telle une porte du $\mathrm{XV}^{\mathrm{e}}$ siècle fossilisée dans un jardin, ou que sont apparues des données évidentes, et cependant jamais formulées, comme cette plate-forme remblayée du " terrain du patronage ». Mais il manquait à cette

3. Thèse en cours d'Anaïs Casaubon, sous la direction de Nicolas Faucherre, Université de Nantes.

4. PRÉAulX, Joseph de, Notice généalogique et historique sur Pouancé et La Guerche, Paris, 1832.

5. Godivier, Henri, Histoire de Pouancé et des environs, Poirier frères, Mayenne, 1906.

6. Meuret, Jean-Claude, "Origines et débuts des villes de la marche bretonne ", dans ChÉDEVILLE, André et Pichot, Daniel (dir.), Des Villes à l'ombre des châteaux. Naissance et essor des agglomérations castrales en France au Moyen Âge, PUR, 2010, p. 43-64.

7. Nous adressons l'un et l'autre, tous nos remerciements à Mme Schreiner, passionnée de la ville de Pouancé, qui a su nous faire ouvrir les lieux les plus privés : ancienne chapelle Saint-Pierre, caves, tours, jardins... pour notre plus grand profit. 
approche archéologique et médiévale, l'étude de documents archivistiques plus récents. Pour Pouancé, ceux-ci ont été filtrés depuis plus de trente ans, et publiés, pour partie, en 2010, dans un ouvrage consacré à l'histoire de Pouancé et du Pouancéen ${ }^{8}$. Certains sont des actes de vente, d'autres des afféagements ou des délimitations foncières, parfois des aveux, des jugements du présidial; certains, tout aussi précieux, sont des plans antérieurs ou postérieurs à la Révolution. Ces sources, souvent négligées par les archéologues et les médiévistes, au prétexte qu'elles sont postérieures, en réalité parce que la masse de documents à filtrer les effraie quelque peu, constituent pourtant de véritables gisements pour une recherche régressive. Elles doivent nécessairement être consultées et donner lieu à des collaborations comme la nôtre dans ce travail. Leur intérêt tient d'abord au fait que le droit de l'Ancien Régime, foncièrement conservateur, tend toujours à appuyer sa procédure et ses actes sur des preuves d'ancienneté, voire d'antiquité : on peut ainsi voir un seigneur du XvII ${ }^{\mathrm{e}}$ siècle recevoir puis faire rédiger l'aveu d'un vassal sur la motte proche de son manoir, vieille de 500 ans, parce qu'elle est signe d'ancienneté de seigneurie ${ }^{9}$; ou bien un frère grandmontain de La Primaudière de la fin du $\mathrm{XV}^{\mathrm{e}}$ siècle argumenter âprement tout au long de vingt et une pages pour défendre ses droits sur la forêt seigneuriale voisine et pour cela, produire et analyser mot à mot l'acte de fondation de sa celle, daté de $1207^{10}$; ou encore, M. Proust, prieur de la Madeleine de Pouancé s'évertuer en 1749 à décrypter l'acte de fondation de son prieuré de 1094 pour pouvoir mieux défendre ses droits face aux appétits du seigneur de Pouancé, le duc de Villeroy, demandant même à l'archiviste de Marmoutier de consulter Du Cange pour savoir si l'énigmatique Degeteria ne pourrait signifier fossé ou douve ${ }^{11}$. Et puis parce que ces actes, surtout ceux des XVII ${ }^{\mathrm{e}}$ et XVIII ${ }^{\mathrm{e}}$ siècle fournissent quantité de renseignements écrits d'ordre juridique, foncier, architectural, viaire, économique que les chartes du Moyen Âge - rares et souvent elliptiques - ne livrent qu'avec parcimonie. Sans doute la plus grande partie d'entre eux renvoie-t-elle à des faits ou à des activités tardives. Mais tout comme sous une couche archéologique récente peut se cacher un niveau inférieur antique ou préhis-

8. NEAU, André, Sur les chemins de l'Histoire en pays pouancéen, 2010, chez l'auteur, $256 \mathrm{p}$.

9. Arch. dép. de la Mayenne, 9J12, septembre 1616, Offre de foy et hommage par Joachim Mordrec pour la Chevrie au seigneur de Brécharnon.

10. Arch. dép. du Maine-et-Loire, 1 H 10, p. 1 et suivantes (1470 apr.), Remontrances a la seigneurie de Chasteaubriend touchant aulcuns griefs faictz a la Primaudière par les officiers.

11. Arch. dép. du Maine-et-Loire, 43 H1/6, 11 novembre 1749, Lettre du prieur de Pouancé Proust au garde du trésor des chartes de Marmoutier : « ne pourrait-on pouvoir trouver un mot latin des siècles 1094 et au-dessous, pour signifier, un fossé, une douve qui entoure, environne une ville, un château, un bourg ou fauxbourg. Dejecteria pouroit-il expliquer fossé ou douve? "Sept siècles après la fondation, la question de M. Proust visait à prouver l'ancienneté des privilèges du bourg des moines. Neuf siècles plus tard, nous l'avons rejoint dans ce questionnement, mais pour de toutes autres raisons, archéologiques et historiques, nous posant exactement la même question de la clôture du bourg prieural (voir dernier chapitre)! 
torique, le texte peut receler lui aussi des strates : on le verra par exemple dans un procès-verbal de visite de 1784 (27 pages), dont un premier niveau de lecture renseigne avant tout sur une querelle de bornage de jardins entre deux voisins, tout à fait immédiate, mais dans lequel, au détour d'un relevé de terrain, le géomètre note accessoirement la présence d'une, puis de deux bases de tours en ruines, avant de conclure, en véritable archéologue, à la présence d'une ancienne porte de ville. Or, celle-ci est absente de toutes les autres sources écrites et on n'en voit rien sur le terrain. Il s'agit là d'une véritable découverte archéologique, mais faite dans un texte.

Une telle recherche nécessite immersion complète, questionnement incessant, et va et vient répétés entre textes et terrain. Et c'est ainsi, à partir de la confrontation nécessaire et approfondie de ces multiples approches - visites et observations de terrain, lecture des chartes médiévales, des aveux de la fin du Moyen Âge, filtrage des archives d'Ancien Régime que l'on a pu commencer à comprendre l'évolution biologique de la ville, depuis le $\mathrm{XI}^{\mathrm{e}}$ siècle. Le tableau synthétique des mentions et traces de tours et portes de ville en est une première illustration (fig. 1). Mais on verra aussi que tous les développements sont accompagnés de plans très détaillés. Leur confection a toujours été menée de front avec l'écriture. Ils ne sont pas de simples illustrations, mais bien au-delà, des aboutissements de la réflexion générale. Ils participent pleinement au discours.

\section{Les origines de la ville de Pouancé}

Des découvertes archéologiques anciennes ou récentes faites dans le Pouancéen, il en est peu qui puissent être mises en relation avec les débuts de la ville. On doit cependant retenir le passage de l'important itinéraire romain Angers-Carhaix à Pouancé, probablement dans l'ancienne ville même. Il s'agit d'un axe peu étudié pour cette région est de la Bretagne. Son tracé est-ouest abordé en $1992^{12}$ est pourtant indiscutable. Sur le cadastre de 1833, à Pouancé même et dans l'agglomération proche, elle n'est pas discernable en raison du développement urbain. Mais sur le terrain et sur les plans, dès qu'on sort de la ville à $1 \mathrm{~km}$ à l'ouest et $2 \mathrm{~km}$ à l'est, son tracé très rectiligne a été conservé sous la forme de chemins, limites parcellaires ou limites paroissiales sur de longues distances. À l'est, on l'observe à partir de Vergonnes, dès la sortie de la forêt d'Ombrée où la tradition le désigne de façon caractéristique comme "chemin vert ". On le suit après jusqu'à l'entrée de Pouancé, fossilisé par des tronçons de chemins et limites parcellaires, plus ou moins en pointillé, et comme limite nord de la commune d'Armaillé. À l'ouest, il commence après l'aérodrome, et apparaît ensuite très bien conservé sous la forme d'un chemin rectiligne presque continu sur plus de $4 \mathrm{~km}$, qui passe ensuite au Dougilard en Soudan (44), pour continuer au nord de Châteaubriant, et filer vers l'ouest. C'est là justement qu'il

12. MeurEt, Jean-Claude, Peuplement, pouvoir et paysage sur la marche Anjou-Bretagne, des origines au Moyen Âge, Société d'Archéologie et d'Histoire de la Mayenne, 1993, p. 206-209. 
est mentionné dans la pancarte de Carbay au milieu du XI ${ }^{\mathrm{e}}$ siècle ${ }^{13}$ comme délimitation au nord de cette villa : "viam publicam Novae Villae quae ducit in Britannia et in Andegaviam " (voie publique de Neuville qui conduit en Bretagne et en Anjou). Aujourd'hui encore, il forme toujours la limite nord de Carbay, à partir du lieu-dit l'Année Vingt. On le trouve aussi mentionné dans d'autres textes du XII ${ }^{\mathrm{e}}$ siècle, plus loin vers Châteaubriant, par exemple comme " via antiqua ». À ce fort faisceau d'indices s'ajoute la mention au XIX d'un fragment de borne leugaire employé comme pierre de crieur à ChazéHenry, à $2 \mathrm{~km}$ au nord du tracé. Si l'on tente de relier ces tracés rectilignes conservés à l'est et à l'ouest, l'itinéraire passe exactement dans la ville, et même dans le bourg de la Madeleine dont on verra plus loin l'importance et la précocité. Mais cette liaison sur le site même de Pouancé se fait avec un léger changement d'axe, une inflexion, comme on en observe parfois sur les voies antiques, au franchissement présumé des limites de civitates : or, ici, il y de fortes probabilités pour que Pouancé, se soit trouvé il y a 2000 ans au contact des cités des Andes à l'est et des Namnètes à l'ouest. Pour autant, aucun site gallo-romain n'a été reconnu à Pouancé même, le plus proche observé se trouvant dans le bois de Verzée, sur la commune de Pouancé, mais à $3 \mathrm{~km}$ à l'ouest.

Beaucoup plus intéressant est le site du haut Moyen Âge déjà décrit dès $1993^{14}$ à l'église de Saint-Aubin qui fut le centre paroissial de Pouancé et le resta jusqu'au XVIII ${ }^{\mathrm{e}}$ siècle. Ce site se signale par la présence de très nombreux fragments de calcaire coquillier remployés dans les murs de l'église à diverses époques, en particulier dans le mur nord de la nef. Ce matériau est totalement absent aux environs immédiats sur la carte géologique; nulle part, on ne le connaît (r)employé ailleurs que dans des églises ou dans leur environnement immédiat; quelques petits gisements ont existé ici et là (Chazé-Henry, Soudan...) mais sans doute insuffisants pour permettre la taille de sarcophages monolithiques, ceux-ci provenant probablement du Saumurois. Le contrefort d'angle nord-ouest de l'église contient même à sa base un fragment d'angle de cuve, ce qui écarte les ultimes doutes qu'on pourrait avoir sur l'emploi originel du matériau. Jamais aucune découverte de sarcophage n'a été signalée autour de l'église, il est pourtant évident que celle-ci est édifiée sur une nécropole semblable à ce qu'on connaît par la fouille (Bréal, Bais, Visseiche, Thourie, Retiers... en Ille-et-Vilaine) ou par des découvertes anciennes en haute Armorique (Béré-Châteaubriant en Loire-Atlantique, Cuillé en Mayenne, Vitré en Ille-et-Vilaine...). Archéologues et historiens ne peuvent que se réjouir de cette pratique qui a consisté depuis le Moyen Âge à placer dans les murs des nouvelles églises ces fragments de sarcophages, signaux de pierre, à fonction mémorielle.

À propos de ces nécropoles du haut Moyen Âge, il a été montré que dans de très nombreux cas de cette région de haute Bretagne et d'Anjou, elles

13. Cartae de Carbaio, publié par MARChEGAY, Paul, Archives d'Anjou, t. II, Angers, 1853 p. 2.

14. Meuret, Jean-Claude, Peuplement, pouvoir et paysage ..., p. 280. 
se trouvent souvent proches des châteaux qui apparaissent au $\mathrm{xI}^{\mathrm{e}}$ siècle. De tels couples existent à Vitré-nécropole disparue, Béré-Châteaubriant, Rannée-La Guerche, Saint-Aubin-Pouancé, Machecoul-Sainte-Croix-La Chaume, etc. Il apparaît qu'elles matérialisent un regroupement des humains - sinon des vivants, au moins des morts - qui préfigure la création des villages et bourgs autour des églises et des châteaux au XI ${ }^{\mathrm{e}}$ siècle Pour des raisons de topographie peu favorable, les châteaux ont souvent du s'installer à quelque distance de ces centres paroissiaux anciens, $1 \mathrm{~km}$ pour ce $\operatorname{cas}^{15}$. Souvent par la suite, et il en est ainsi à Pouancé, les puissants châteaux de la frontière bretonne n'amenèrent pas la création de nouvelles paroisses ${ }^{16}$ : les châtelains préférant au contraire favoriser le développement de bourgs prioraux parfois multiples, moins concurrentiels, favorable au développement des échanges et donc à l'accroissement des revenus banaux.

\section{La ville au Moyen Âge dans les textes}

Si les données archéologiques présentées ci-dessus constituent le substrat de la ville de Pouancé, il n'en demeure pas moins que celle-ci constitue avant tout une agglomération castrale. C'est là un phénomène qui concerne tout l'Occident médiéval, surtout à partir du XI ${ }^{\mathrm{e}}$ siècle. Cependant, les textes et les données historiques disponibles permettent d'affiner le cas de Pouancé, en montrant en particulier l'importance de sa position à la limite de l'Anjou et de la Bretagne.

Pouancé apparaît dans la pancarte de Carbay ${ }^{17}$ au milieu du XI ${ }^{\mathrm{e}}$ siècle. Celle-ci a été rédigée par l'abbaye de Marmoutier pour enregistrer la donation de la villa de Carbay faite par le comte d'Anjou Geoffroy. Cette cession s'inscrit dans le cadre d'une forte opposition entre deux châteaux préexistants, l'un en Bretagne, tenu par Brient - c'est le futur Châteaubriant - et l'autre en face en Anjou, contrôlé par le comte d'Anjou, et tenu par un vicarius du nom de Landry. Le comte Geoffroy reçoit alors un moine de Marmoutier nommé Jonas, obligé d'abandonner son prieuré de Marcillé (Robert, en Ille-et-Vilaine) à cause de la guerre que se livrent les seigneurs de Vitré et de Châteaubriant. En donnant à Marmoutier le territoire de Carbay, le comte établit un territoire-tampon, une sorte de sanctuaire, entre son château de Pouancé et celui de Brient, juste à la limite Anjou-Bretagne; en fait derrière le terme villa employé pour désigner le territoire délimité, il s'agit bien de la création d'une paroisse. Dans la même pancarte, un petit peu plus tard, le château change de gardien et passe aux mains de Hervé de Martigné, toujours pour le comte d'Anjou. Ce Hervé était alors le déten-

15. MeurEt, Jean-Claude, Peuplement, pouvoir et paysage..., p. 329-330.

16. Étude en cours du maillage paroissial le long de la frontière est de la Bretagne.

Comme en Indre-et-Loire, très peu de châteaux ont engendré de nouvelles paroisses.

17. Cf. note 3 . 
Pouancé ou la constitution d'une ville castrale en Bretagne et Anjou

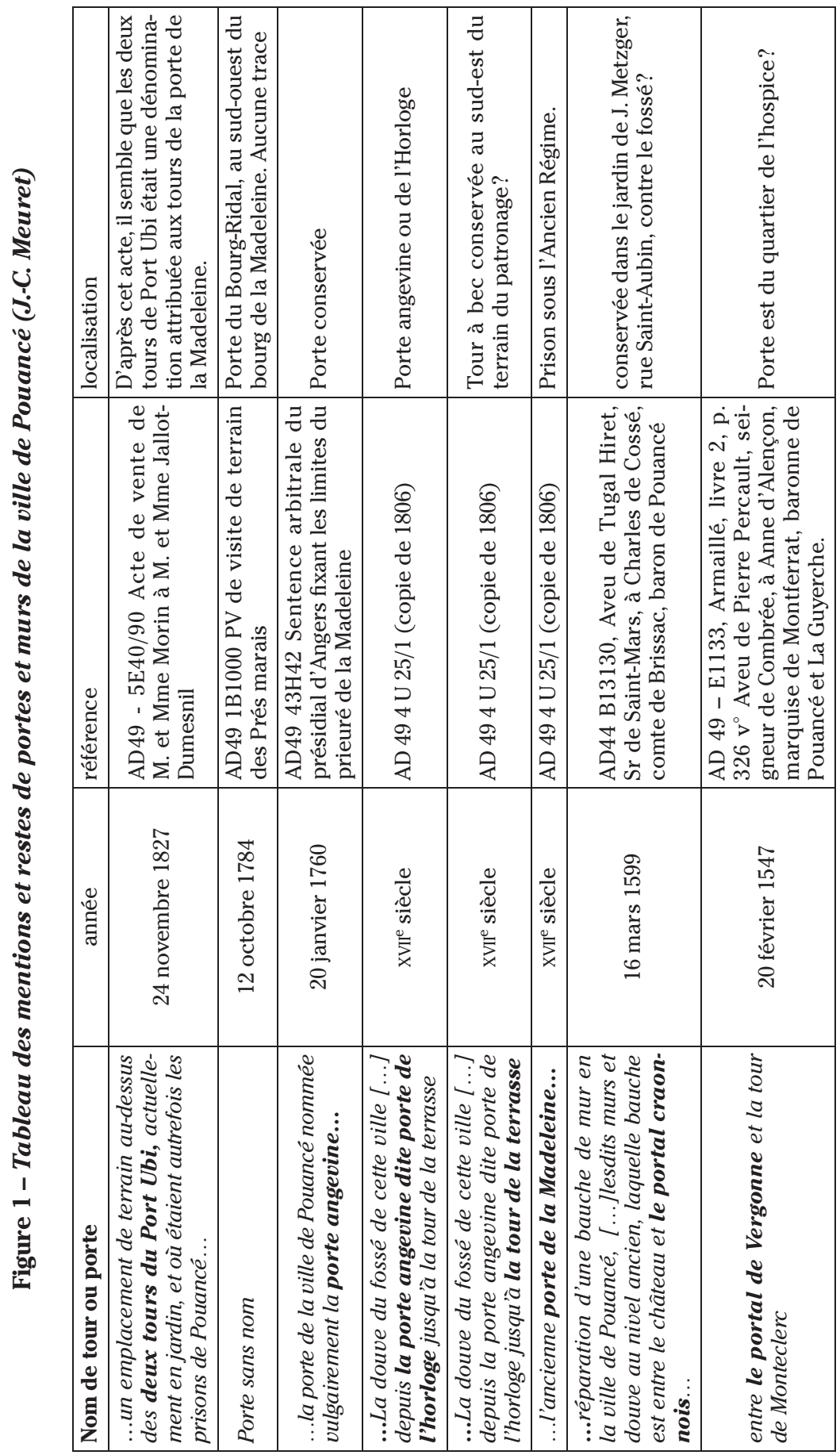




\begin{tabular}{|c|c|c|c|c|}
\hline 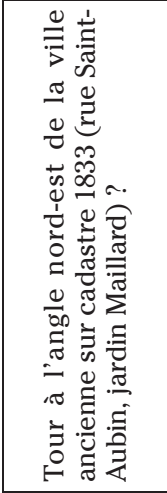 & 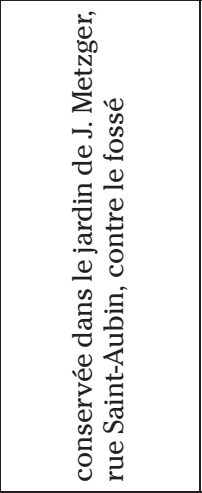 & 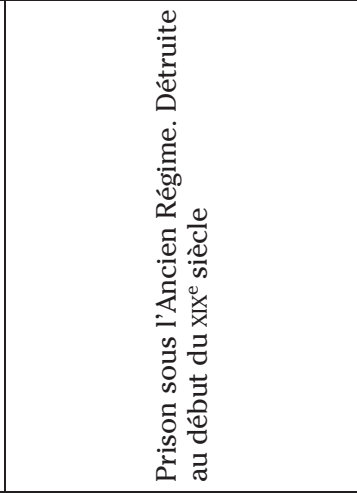 & 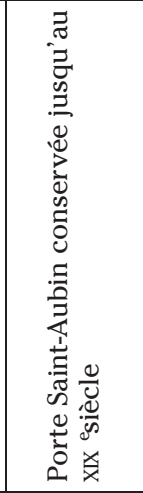 & 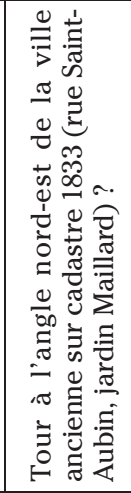 \\
\hline 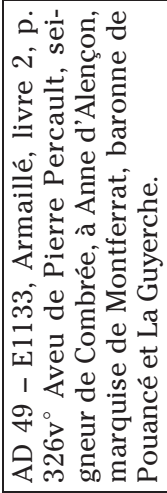 & 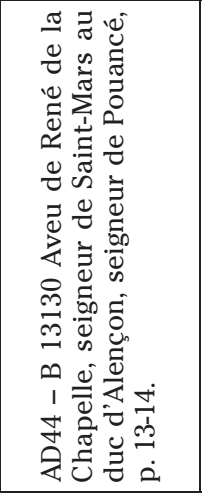 & 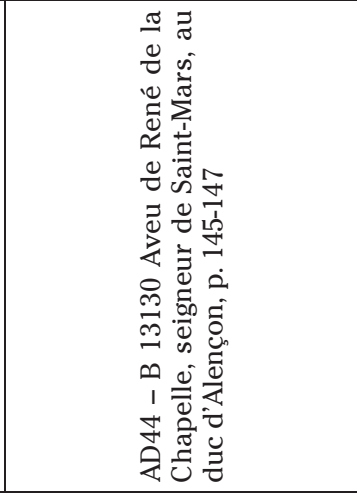 & 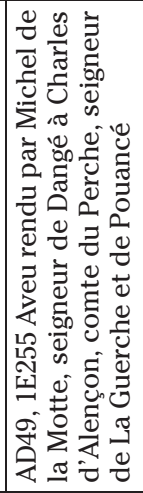 & 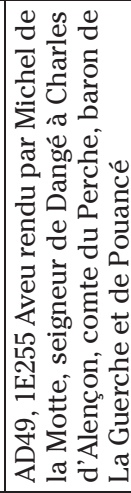 \\
\hline 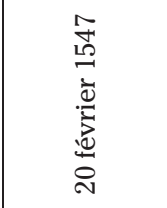 & $\stackrel{m}{10}$ & m & 总 & 동 \\
\hline 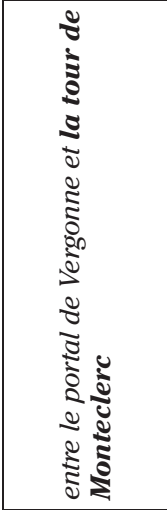 & 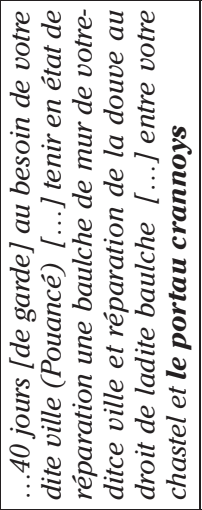 & 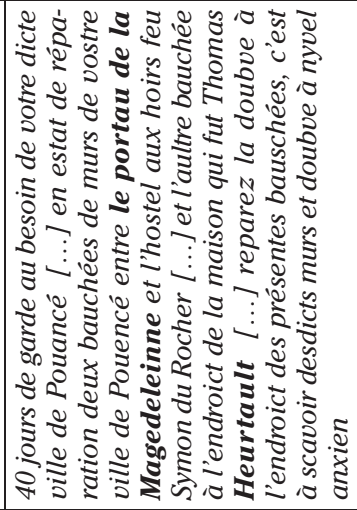 & 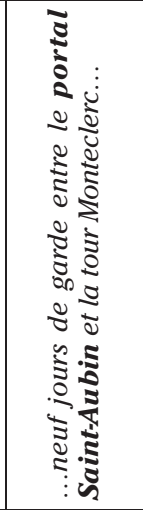 & 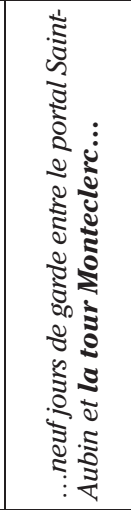 \\
\hline
\end{tabular}




\begin{tabular}{|c|c|c|c|c|}
\hline 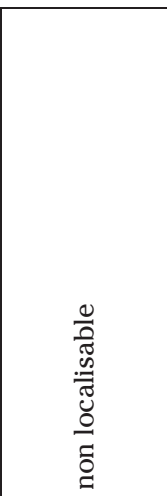 & 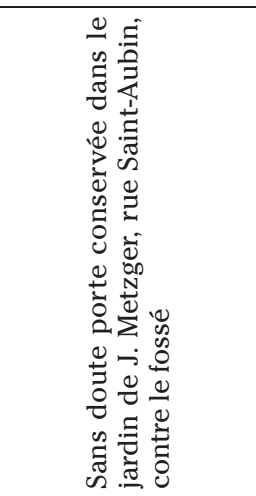 & 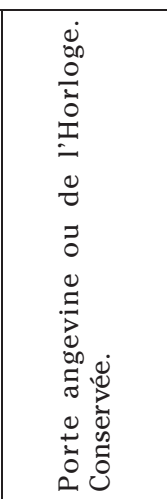 & 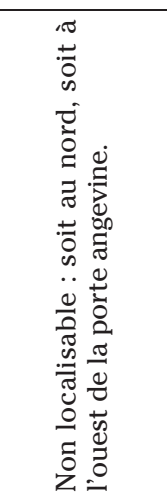 & 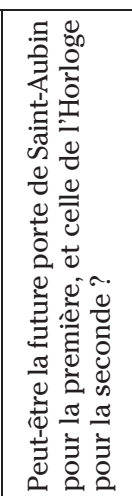 \\
\hline 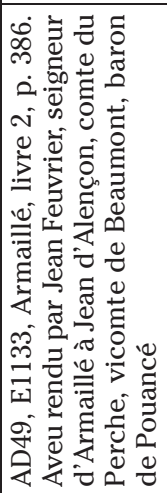 & 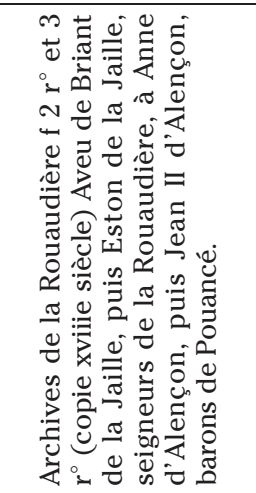 & 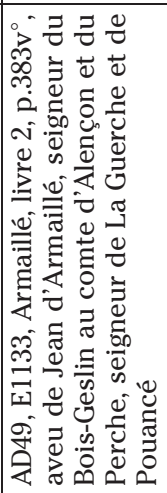 & 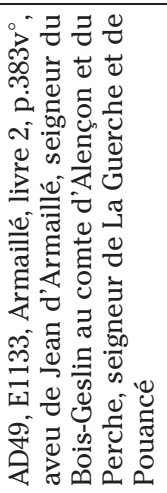 & 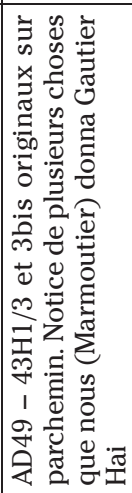 \\
\hline 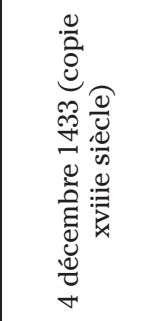 & 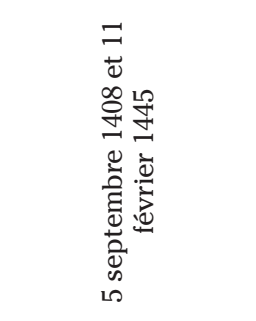 & 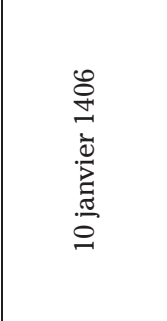 & 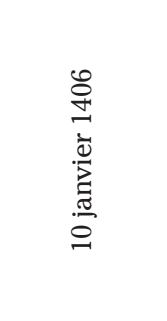 & 용 \\
\hline 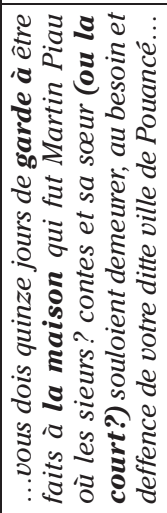 & 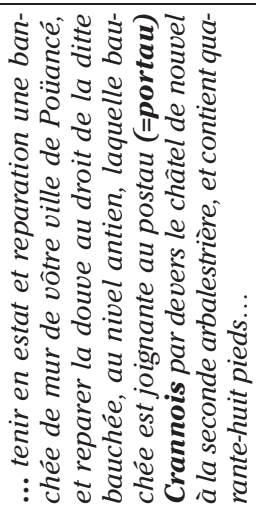 & 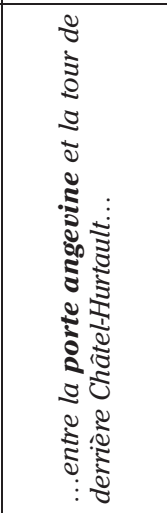 & 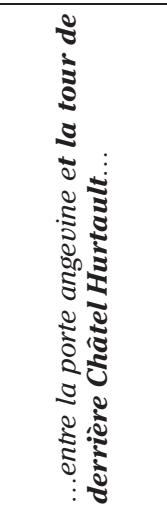 & 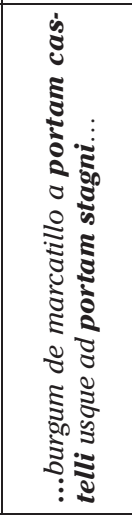 \\
\hline
\end{tabular}


teur du château de Martigné, limitrophe de Pouancé, mais côté Bretagne, à $15 \mathrm{~km}$ au nord-ouest.

Le château ne réapparaît qu'en 1094, tenu cette fois-ci, non plus pour le comte d'Anjou, mais par un dominus autonome nommé Gautier Hai. C'est le fils de Hervé de Martigné. Personnage belliqueux et craint, il procède aussi à des donations pieuses.

Ainsi, en 1094 il dote généreusement le prieuré établi près de son château par Marmoutier ${ }^{18}$. Grâce à cette charte, on entrevoit les débuts de l'agglomération castrale (fig. 2) : une chapelle seigneuriale (mais laquelle? est-ce Saint-Pierre? ou une autre?), un marché, un péage (pedagium), un étang au pied sud de l'agglomération (stagnum de Fonte Britelli), un bourg nommé Marcatillo qui va de la porte du château jusqu'à la porte de l'étang et qu'il est malaisé de localiser précisément. Est-ce le bourg castral, ce qu'on appellera la "ville " sous l'Ancien Régime? Dans ce cas la porte du château serait la future porte Saint-Aubin, et celle de l'étang la future porte angevine car cette dernière ouvre vers l'étang d'alors, celui de Fonte Britelli (Fontaine de Bretault). Mais il peut s'être situé ailleurs, par exemple sous l'actuelle plate-forme vide dans la future ville. Ou encore à l'est du bourg castral, à l'emplacement de l'hopital. Un autre bourg est cité, entre les vignes jusqu'à Degeteria, lieu encore moins facile à placer, à moins comme il a été dit qu'il ne s'agisse du mot dejecteria qui désignerait des rejets de fossé. Apparaissent encore deux fours, l'un seigneurial dans le bourg castral, l'autre prieural que les moines sont autorisés à édifier dans leur propre bourg. Le premier figure encore dans un acte de peu antérieur à 1220, où les moines revendiquent et obtiennent la dîme du fournage ${ }^{19}$. Pour le second, un bail à ferme du XVIII ${ }^{\mathrm{e}}$ siècle montre que les moines en tiraient encore des revenus substantiels à la veille de la Révolution ${ }^{20}$. L'un et l'autre ont aujourd'hui disparu mais on connaît leur position : le premier a été vu rue Saint-Aubin, à l'occasion de terrassements près de l'entrée du château en $1787^{21}$; le second figure sur un plan lors de la prise de possession du prieuré en 1701, à quelques mètres à l'ouest de l'église de la Madeleine ${ }^{22}$. Pour le bourg des moines sont cités des bourgeois (burgenses), ce qui, ajouté au marché, au péage et au nom du bourg - Marcatillo = le petit marché? suggère un important contexte d'échanges. Le passage de l'antique tracé de la via publica d'Anjou en Bretagne dans le bourg même de la Madeleine n'y est pas pour rien. Signe à la fois de la christianisation en cours et de la

18. Arch. dép. du Maine-et-Loire, 43 H1/3 et 3 bis, originaux sur parchemin.

19. Arch. dép. du Maine-et-Loire, 43 H1/8 « quadam controversia intervenisse [...] super decima furnagis de furno castri Poenceius...

20. Arch. dép. du Maine-et-Loire, 5 E 40/52 : 21-05-1762, bail à ferme du four banal du prieuré de Pouancé. Cf. NEAU, André, En pays Pouancéen ..., transcription de l'acte p. 84-85.

21. Arch. dép. du Maine-et-Loire, 1 B 999 : 23 janvier 1787, à l'occasion de terrassements pour l'évacuation des eaux vers la porte Saint-Aubin, à aller vers la prée de Morpiau, est découvert un ancien canal à distance de 6 pieds de la haie dépendant du four à ban.

22. Plan dans NEAU, André, En pays pouancéen..., p. 147. 
croissance démographique de l'agglomération, une église ${ }^{23}$ est construite par les moines, avec l'aide du seigneur et sa consécration est programmée.

\section{Figure 2 - Plan recomposé de Pouancé fin XI siècle (J.-C. Meuret)}

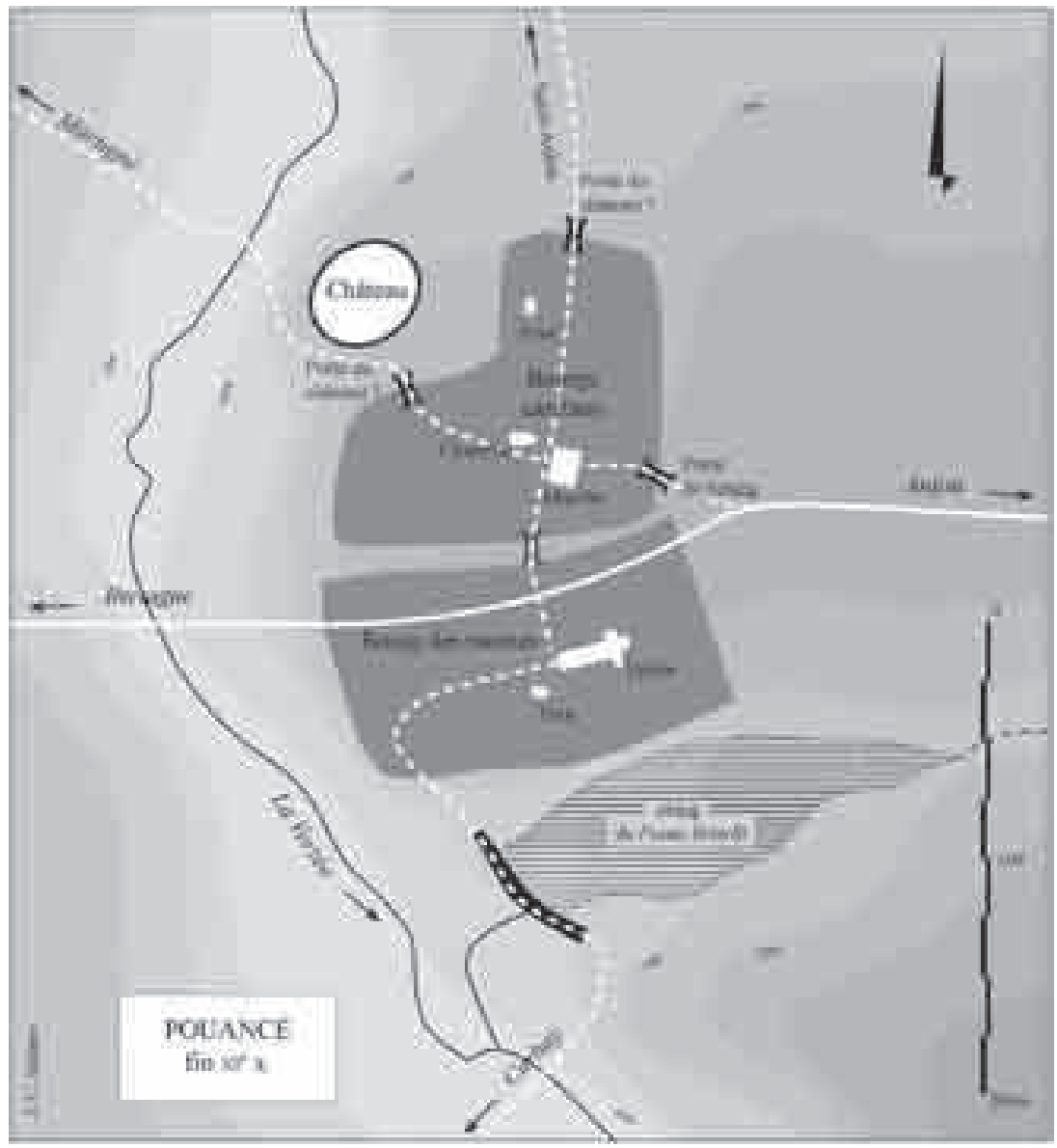

Nulle allusion à une enceinte de pierre autour des bourgs, le fait est d'ailleurs bien rare à l'époque hors des chefs-lieux de cités antiques, mais la présence de deux portes implique au moins l'existence d'une enceinte

23. Dans la deuxième version originale de la charte, il est fait mention de la construction d'une église dont la consécration est prévue : " ... aecclesiam faciemus in burgo nostro... " (Arch. dép. du Maine-et-Loire, 43H1/3bis). Pour autant nous ne pensons pas qu'on puisse s'appuyer sur ce mot ecclesia pour affirmer qu'une paroisse est créée. Il faudra attendre plusieurs demandes des habitants de la ville pour qu'en 1776 l'église de la Madeleine soit érigée en succursale de Saint-Aubin, puis le 4 mars 1778 pour qu'elle devienne paroisse de plein droit (NEAU, André, En pays pouancéen..., p. 149-152). 
de terre et de bois. On retiendra le nombre de bourgs, trois ou quatre, ce qui n'est pas une rareté à cette époque, loin de là (Fougères en comptait cinq, peut-être sept), pas plus en Bretagne, que dans les Pays-de-la-Loire ou en France en général. Il s'agit bien d'une agglomération générée par le château, et comme souvent ailleurs, elle présente une organisation éclatée, multipolaire.

Il faut atteindre un siècle, aux environs de 1220 ou quelques années avant, pour percevoir une autre image de l'agglomération, fournie par une remarquable charte de donation demeurée inédite (fig. 3). Le donateur est Guillaume III de La Guerche ${ }^{24}$. En effet, depuis les années 1120, par le mariage d'Emma, fille et héritère de Gautier Hai avec Guillaume I $^{\text {er }}$ de La Guerche, les trois châtellenies de Martigné, Pouancé et La Guerche ne font plus qu'une au plan seigneurial, et ce malgré la frontière Bretagne-Anjou qui est censée les séparer ${ }^{25}$.

Cette longue charte clôt un conflit entre les moines et le seigneur, à propos de la dîme du nouvel étang, celui de Saint-Aubin, qui se trouve toujours au pied du château. Elle s'inscrit sur fond d'un plus grave conflit, celui qui oppose depuis des années ce Guillaume III à Bérengère de Navarre, veuve de Richard Cœur-de-Lion. Avec le soutien des papes, celle-ci tente en effet de récupérer la terre de Segré qui faisait partie de son douaire. Mais, ces évènements se déroulent aussi sur fond de grands changements politiques dan l'Ouest, et en France, en particulier l'expulsion des Plantagenets et la confiscation par la monarchie montante, des terres de Jean-Sans-Terre, parmi lesquelles l'Anjou. En même temps, les villes naissantes sont un des enjeux de ces conflits, Segré en premier lieu pour Guillaume III de La Guerche. En 1207, d'ailleurs, lorsqu'il fonde la toute proche, celle grandmontaine de La Primaudière en association avec Geffroy de Châteaubriant, il a bien pris soin de doter cet établissement de quatre bourgeois (" des francs bourgeois "), un à La Guerche, un autre à Martigné, un troisième à Pouancé et le quatrième à Segré. C'est là une subtilité stratégique, fréquente à cette époque, qui consiste à sanctuariser des lieux par une fondation pieuse; on doit aussi y voir le signe du développement urbain, ou du moins des bourgs castraux.

La charte des années 1220 permet d'observer le très net développement de l'agglomération castrale depuis Gautier Hai : l'objet du différend est ce nouvel étang nommé stagnum apud Pouenceius que Guillaume III vient de créer. C'est l'actuel grand étang de Saint-Aubin, dont la chaussée est installée au pied même du château, à la faveur d'un fort resserrement de la vallée de la Verzée en cet endroit. Le bourg des moines (burgum monachorum)

24. Arch. dép. du Maine-et-Loire, 43 H1/6.

25. Cf. l'étude approfondie du lignage de La Guerche Pouancé : MeuRET Jean-Claude, " Au cœur de la marche bretonne, l'ascension et le démantèlement d'une grande châtellenie, La Guerche-Pouancé (milieu XI -milieu XIII ${ }^{\mathrm{e}}$ siècle) ", dans QuAGHEBEUR, Joëlle et SolEIL, Sylvain (dir.), Le Pouvoir et la foi au Moyen Âge en Bretagne et dans l'Europe de l'Ouest, mélanges en mémoire du professeur Hubert GuILLTEL, PUR, 2010, p. 639-684. 
Figure 3 - Plan recomposé de Pouancé au XIII siècle (J.-C. Meuret)

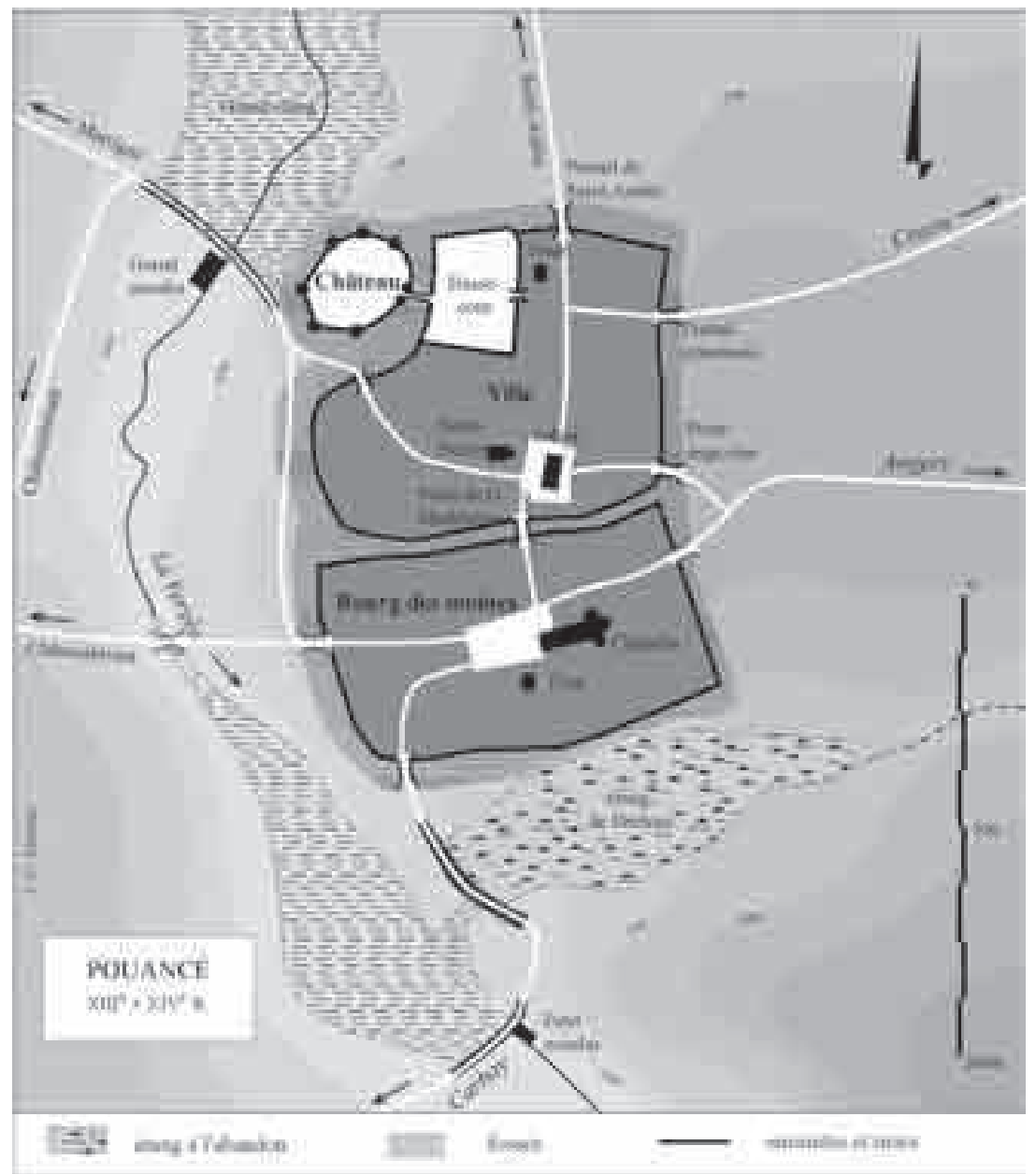

apparaît bien sûr à propos des hommes des moines et des hôtes (hostes) qui s'y trouvent. Il en est de même pour les bourgs du seigneur désignés soit par le terme global castrum, soit par le burgus feodum. Les habitants y sont soit des mansionarii, soit des burgenses castri, soit des hostes. On cite l'ancien marché (antiquam merchatum) et les mesures pour céréales en usage; ce ne sont pas les mêmes dans le bourg des moines et dans celui du seigneur. Celui-ci donne la dîme de son marché. Hautement révélatrice de l'activité marchande croissante et de son contrôle par le seigneur, une cohue est citée (cohua mea), c'est-à-dire une halle qu'il faut comprendre comme un bâtiment destiné à abriter le marché, mais aussi la place qui l'entoure avec des étals (stalla). En fait, ici comme ailleurs, la cohue est un 
droit seigneurial, désigné dans la même charte comme ius cohua, et l'éventualité du cas de son transfert par Guillaume III est envisagée dans le texte. Cet acte se révèle sur ce point de la cohue presque aussi riche que celui qui traite de celle de Machecoul en $1238^{26}$ : il s'agit d'un droit de contrôle et de taxation du marché que le seigneur regroupe sur une place en y édifiant une halle (la cohue) et en autorisant la construction de maisons à porches ou d'étals (porticas à Machecoul, stalla à Pouancé). Le seigneur de Pouancé a un four, mais les moines ont aussi le leur, celui que Gautier Hai les avait autorisés à créer en 1094. Des maisons sont bâties, sans doute surtout en bois, car il est stipulé que lorsque les moines voudront bâtir, ils pourront disposer de bois vif dans les forêts du seigneur. Les moulins tout proches, liés à l'étang neuf, sont encore des moulins à céréales, car il est entendu que la recette du moulinage (moltura) sera placée dans un coffre à double clé, une pour le seigneur, une pour le prieur; le procédé existe ailleurs, par exemple à Marcillé-Robert. Cependant, ces moulins peuvent se multiplier, car des progrès techniques sont survenus : il est envisagé le cas où le seigneur construirait des moulins foulerets (molendini fulloni) pour le drap, ou à écraser le tan (ad tamnum pilandum).

Constatons que dans cette charte si riche en beaucoup de points, il n'est malheureusement fait nulle mention d'éventuels murs, fossés ou portes de l'agglomération. C'est simplement parce que ceux-ci ne concernaient en rien le conflit de redevances entre le seigneur et les moines. On ne sait donc pas s'il existait une enceinte urbaine muraillée - qui serait aussi précoce que celle de Vitré -, simplement des fossés, ou si les différents bourgs avaient leur propre clôture.

Deux siècles passent et en 1406 et 1408 apparaître la clôture de la ville (fig. 4). On en doit les mentions au fait que les d'Alençon, seigneurs de Pouancé, imposaient à leurs vassaux directs, parmi d'autres devoirs, de garder et parfois d'entretenir les murs de la ville. Nous avons donc assidûment cherché les aveux rendus à cette époque. En 1406, Jean d'Armaillé doit 15 jours et 15 nuits de garde dans Pouancé, " entre le portail SaintAubin et la tour derrière Châtel Hurtault ${ }^{27}$ ". Le premier désigne la porte Saint-Aubin au nord, qui subsistera jusqu'au XIX ${ }^{\mathrm{e}}$ siècle; la seconde n'est pas identifiée à ce jour, peut-être une tour de ville à l'angle nord-ouest de celle-ci, proche de la basse-cour du château. Confirmant le précédent, un aveu, aussi recopié au XVIII ${ }^{\mathrm{e}}$ siècle, est rendu en 1408 au duc d'Alençon ${ }^{28}$ seigneur du lieu, par le seigneur de La Rouaudière. Il y est fait mention du mur de la ville et d'arbalétrières; le vassal doit fournir des corvées pour " tenir en estat et reparation une banchée de mur de votre ville et reparer

26. Cartulaire des sires de Rays, publié par Blanchard René, Archives historiques du Poitou, XXX, 1889, p. 101, acte CXXXIII.

27. Arch. dép. du Maine-et-Loire, E 1133, Armaillé, livre 2, p. 383 vº 10 janvier 1406 , copie XVIII ${ }^{\mathrm{e}}$ siècle.

28. Archives privées de la seigneurie de La Rouaudière (Mayenne), aveu rendu par Briant de la Jaille, puis Eston de la Jaille, le premier à Anne d'Alençon, le second à Jean II d'Alençon, seigneurs de Pouancé. 
la douve "; cette banchée est " joignante au posteau craonnois par devers le chatel de nouvel à la seconde arbaletriere et contient quarante huit pieds ". Le même aveu est rendu dans les mêmes termes en 1445 avec la même mention du postau craonnois. Mais cet acte ne nous est parvenu que par une transcription du $\mathrm{XvIII}^{\mathrm{e}}$ siècle, probablement fautive : ce qui $\mathrm{y}$ est transcrit posteau ou postau, doit être décrypté porteau ou portau. En effet, le terme désigne au Xve siècle un portail, une porte ${ }^{29}$. Ce n'est donc pas le poteau craonnois, mais la porte, le portail craonnais (qui ouvre vers la ville de Craon). Cette porte, portail ou poterne ne figure dans aucune des pièces postérieures lues à ce jour et n'était donc pas localisée. Nous y reviendrons dans le dernier chapitre à propos d'un vestige en élévation qui semble bien lui correspondre. Quoi qu'il en soit, en 1408, il est certain que la ville est close par un mur de pierre, qu'elle est dotée de tours à arbalétrières, au moins au niveau des portes. Beaucoup d'autres villes en possèdent : Vitré depuis le début du XIII ${ }^{\mathrm{e}}$, et la plupart des villes équivalentes au cours de ce même siècle. On a confirmation de ce texte et de la lecture qui en est proposée, dans des aveux postérieurs rendus à la seigneurie de Pouancé. En 1507 sont cités le "portal Saint-Aubin et la tour Monteclerc $^{30}$ ". Le premier désigne la porte Saint-Aubin au nord, mais la seconde n'est, à ce jour, pas localisée avec certitude. Elle tire sans doute son nom d'une famille Monteclerc possessionnée à Armaillé, Vergonnes et Combrée en 1404, et dont un membre peut avoir eu la responsabilité militaire ${ }^{31}$. Soit il s'agit d'une tour qui aurait précédé la forte tour d'artillerie conservée un peu à l'ouest, à $30 \mathrm{~m}$ de là, qui protège l'angle nord-est de la basse-cour du château, ou plus sûrement s'agit-il de la tour portée sur le plan Godivier à $40 \mathrm{~m}$ à l'est, à l'angle nord-est du mur de la ville, et dont l'emprise est visible sur le plan cadastral de 1833. En 1513 et 1599, deux autres aveux précisent presque exactement les mêmes devoirs d'entretien des murs et de la douve ${ }^{32}$ en faisant eux aussi mention de banchées de

29. Sur la copie du XVIII ${ }^{\mathrm{e}}$ siècle, la graphie des $\mathrm{s}$ et des $r$ est très proche. De plus, il est logique de délimiter un tronçon de douve et de mur de ville par une porte. Beaucoup moins par un poteau. GODEFROY Frédéric, Dictionnaire de l'ancienne langue française et de tous ses dialectes, du $I^{e}$ au $X V^{e}$ siècle, 1901, p. 314 : portaul, voir portal; p. 312 portal = portail, porte. Ex : Ce furent quatre portaulx bien garniz de gens du duc de Bourgogne et ses bannières dessus (Comminges, Mémoires, III, 3, Chantelauze). LA CuRne de SAInte-Palaye, Dictionnaire de l'ancien langage français ou glossaire de la langue française : depuis ses origines jusqu'au règne de Louis XIV, Champion, Niort, $1875-1882$, t. 8 ; p. 382 : portal, portaus = portail, porte de ville. Ex : Si a quatre portaus dont li murs sont espes et haut. Mais p. 390 : posteau, postel, posteaulx = poteau (au sens de poteau ou d'amis).

30. Arch. dép. Maine-et-Loire, 1 E 255.

31. Arch. dép. Maine-et-Loire, 140 J 56. Aveu rendu par Catherine Du Guesquin, veuve de Charles de Rohan, au duc d'Alençon, alors seigneur de Pouancé pour ses fiefs des paroisses d'Armaillé, Vergonnes, Combrée et Noëllet. Parmi les hommes de foi simple, figure à neuf reprises Charles de Monteclerc, possessionné à Noëllet et Combrée.

32. HALBert, Odile, L'Allée de la Hée des Hiret, gentilhommes mi-bretons, mi-angevins, éd. O. Halbert, 2000, p.61-63, aveux aux Archives départementales de Loire-Atlantique, B 13130 . 
mur. Ce terme désigne un mode de construction des murs par coffrage, banchées comme on le dit aujourd'hui encore ${ }^{33}$.

\section{Figure 4 - Plan recomposé de Pouancé au $\mathrm{XV}^{e}$ siècle (J.-C. Meuret)}

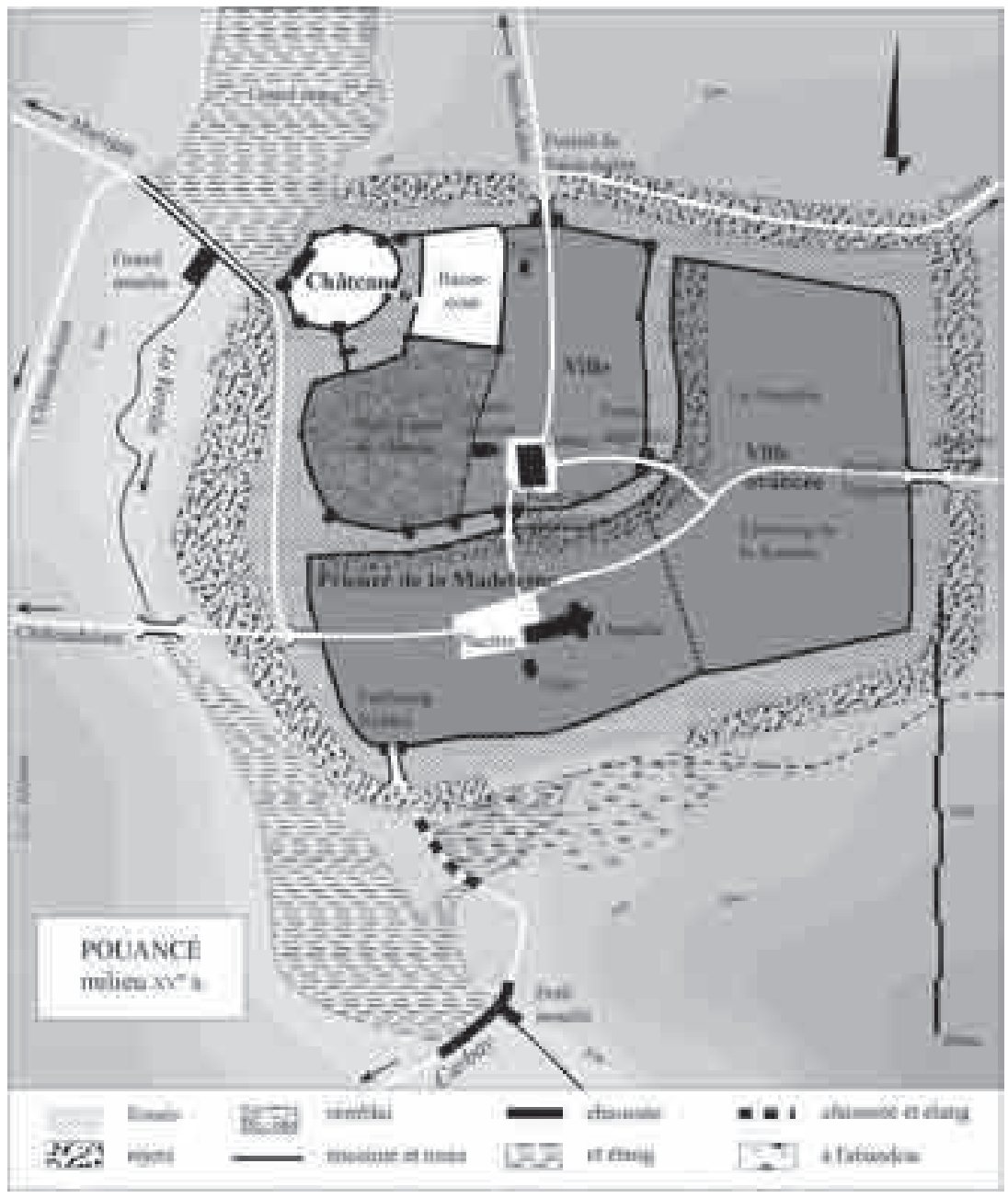

Depuis la fin du XIV siècle et au cours du XV ${ }^{\mathrm{e}}$ siècle, la place de Pouancé est plusieurs fois assiégée (1379, 1431-1432 et 1443) ou utilisée comme base militaire (1472 et 1488). Il n'est pas question ici d'entrer dans le détail de ces évènements qui concernent d'ailleurs autant sinon plus le château proprement dit que la ville. Cependant, lorsque Louis XI s'installe

33. Cf MEuret, Jean-Claude, " Origines et débuts des villes... ", p. 57-58, note 126. 
à Pouancé en juillet 1472, et en fait sa base pour ses opérations en haute Bretagne, il dirige une armée importante et de plus dotée d'une puissante artillerie $^{34}$. Le seul espace du château primitif ne peut suffire à abriter ces hommes et cet équipement. De même, en 1488, lorsque Louis II de La Trémoille fait de Pouancé sa base logistique pour attaquer la Bretagne ${ }^{35}$, son armée est dotée de la plus puissante artillerie d'Europe et elle compte 11000 hommes. Trois ans plus tard, Pouancé, en même temps que Vitré et Redon est encore choisie comme base de départ pour une armée française de 50000 hommes, à nouveau menée par La Trémoille pour une nouvelle et décisive opération contre la Bretagne ${ }^{36}$. Dans tous ces cas de figure, ni ces masses humaines, ni ces précieuses armes à feu ne peuvent avoir été installées dans la modeste enceinte du château primitif qui n'atteint pas $3000 \mathrm{~m}^{2}$. On y reviendra dans la description de la partie de la ville close nommée " quartier du château " sur le cadastre napoléonien.

Le 26 septembre 1541, Anne d'Alençon, rend aveu au roi pour la baronnie de Pouancé, et là les détails relatifs à la ville abondent ${ }^{37}$. La ville est " close et fermée de murailles, lesquelles murailles sont démolies et rompues en deux endroits ". " Le château et forteresse dudit lieu avec l'enclos pourprix et jardins d'iceluy, le tout contenant huit journaux de terre ou environ"; puis sont cités successivement " le prieuré de la Magdeleine situé es forsbourg dudit Pouancé ". La chapelle de Saint Pierre "sise en ladite ville "; les halles de la ville où se tient le marché chaque jeudi et huit foires annuelles; le grand moulin " sis en la chaussée du grand estang [...]sous le château ", "le moulin appelé le petit moulin estant quelque peu au-dessous dudit Grand moulin "; le moulin à draps appelé " le moulin de terre ". La dame a le droit " de contraindre ses vassaux à la garde de sa ville et de sa personne et réparations des murailles et douves de ladite ville quand le cas echet ". Sont encore évoqués des procès en cours dont certains relatifs aux " réparations des ponts de ladite ville, chaussée desdits étangs et portes d'iceux [...] moulins et halles " que n'ont pas accomplies certains vassaux. Mais si la clôture de la ville par une muraille est clairement énoncée, le texte ne fournit que peu de détails. Pas de mention non plus des portes, et pourtant, elles existent. Et puis il n'est plus question des différents bourgs cités dans l'orbite castrale en 1094 et vers 1220, mais de la ville. Ce dernier mot est à l'évidence la traduction du mot castrum du Moyen Âge central : c'est que comme dans beaucoup d'autres villes, une muraille a été construite pour enclore les différents bourgs, au moins ceux groupés près du château. Son entretien doit être assuré par les différents vassaux, comme on l'a vu d'ailleurs dans l'aveu de 1408. Comme ailleurs, le ou les bourgs monas-

34. CINTRÉ, René, Les Marches de Bretagne au Moyen Âge. Economie, guerre et société en pays de frontière (XIV'-XVe siècles), éd. J.-M. Pierre, 1992, $238 \mathrm{p}$.

35. Correspondance de Charles VIII et de ses conseillers avec Louis II de la Trémoille pendant la guerre de Bretagne (1488), publiée d'après les originaux par Louis de LA TRÉMOLLLE, Paris, 1875, rééditée par Mégariotis Reprints, Genève, 1978.

36. CinTRÉ, René, Les Marches de Bretagne..., p. 160-161.

37. Arch. dép. du Maine-et-Loire, E 1133, f 226. 
tiques - ici celui de la Madeleine, toujours aux mains de Marmoutier - n'est pas englobé dans l'enceinte urbaine. Souvent, c'est en raison de leur éloignement; mais ici, ce bourg prieural est contigu à la ville. C'est bien le signe de statuts juridique et foncier très différents de ceux de la ville du seigneur. Les moulins se sont multipliés tels le moulin à drap et le moulin à tan qui n'étaient qu'envisagés dans l'acte de vers 1220 . On note la présence de la chapelle Saint-Pierre dans la ville. Elle figurait dans le testament de Geoffroy de Pouancé-La Guerche en $1263^{38}$ et elle est mentionnée à la présentation de Marguerite de Lorraine, duchesse d'Alençon vers $1500^{39}$.

Il en demeure encore quelques vestiges qui seront décrits. Un détail mérite attention, celui qui précise que le château avec ses pourprix et jardins mesure huit journaux, soit environ quatre hectares. Cette superficie signifie qu'à la fin du Moyen Âge, on comptait dans le château non seulement la forteresse qui ne mesure qu'un peu plus d'un demi-hectare (fossés et basse-cour compris : cf. tableau de mesures final) mais aussi d'autres espaces, dont un qui sera décrit plus loin.

\section{La ville sur les plans anciens (XVIII ${ }^{\mathrm{e}}$ et 1833)}

\section{Le plan de 1781}

Pour l'Ancien Régime, on dispose de deux plans levés au XVIII ${ }^{\mathrm{e}}$ siècle. Le premier date de $1781^{40}$. (fig. 5) Son tracé n'est pas exactement conforme au terrain : on relève des discordances par rapport aux plans postérieurs ainsi que le manque de détails pour le château et l'absence de la porte de la Madeleine. Cependant, il présente le grand intérêt de figurer une suite de fossés autour du bourg de la Madeleine, à l'est et au sud. Ceux du sud, encore plus ou moins visibles aujourd'hui, seront évoqués dans le dernier chapitre. Mais ceux de l'est à l'intérieur desquels est représenté l'hôpital ne sont pas aussi bien figurés ailleurs car ils ont été comblés plus tôt. Si ce tracé est fiable, cela signifierait que l'enclos de ce bourg prieural était trois fois plus étendu que celui de la ville. Ce qui étonne un peu. D'ailleurs, tout indique que la partie est, celle qui englobe l'hôpital, n'est pas contemporaine du reste, et qu'elle est une extension tardive de la fin du Moyen Âge; il en sera traité plus loin. Un tel agrandissement pourrait se placer $\mathrm{au} \mathrm{XV}^{\mathrm{e}}$ siècle siècle, époque où l'artillerie engendra fréquemment de tels travaux de terre. Sur le plan et sur le terrain, divers indices font penser que le bourg prieural originel n'allait pas aussi loin, et que son fossé est remontait seulement à la porte de l'Horloge, à peu près en suivant l'actuelle rue Clémenceau. Une délimitation du bourg de la Madeleine de 1760 en

38. Cartulaire des sires de Rays, publié par BlanchaRd René, Archives historiques du Poitou, XXX, 1889, p.113.

39. Arch. dép. du Maine-et-Loire, E 1461 (1492-1521) : Marguerite de Lorraine devient veuve de René d'Alençon en 1492, date à laquelle elle est seigneur de Pouancé. Elle meurt en 1521 .

40. Arch. dép. du Maine-et-Loire, C 81. 
fournit pleine et précise confirmation ${ }^{41}$ : elle indique que les limites du fief prieural vont depuis « la porte de la ville de Pouancé nommée vulgairement la porte angevine élevée à l'orient à aller en droit ligne vers midy immédiatement au dessus de la maison du Sieur Letort, de là et en continuant laditte ligne traverser les fossés du faubourg (de la Madeleine) et le chemin qui conduit de la Houairie (= Rouairie?) à la fontaine de Bretault, passer audessus de laditte fontaine et le long de l'ancien lit de l'étang de Bretault, à aller se rendre dans le bas du chemin de Pisseoyzon qui conduit au petit moulin, enclaver par un autre ligne tirée vers le septentrion, tous les jardins, maisons et prés qui aboutissent sur le fossés de l'étang du petit moulin à remonter jusqu'au grand moulin, ce susdit dernier canton appellé vulgairement les prés marais, de là remonter vers orient le long du fossé de ladite ville de Pouancé jusqu'à la surdite porte angevine, compris toutes les maisons et jardins qui sont sur le rejet ${ }^{42}$ dudit fossé... " Ce même plan de 1781 figure trois, et peut-être même quatre portes de ville, les deux premières, celle de Saint-Aubin et celle de l'Horloge dotées de deux tours rondes, conformément aux réalités documentaires et de terrain; une troisième, proche de l'hôpital, ouvrant vers Segré et Angers, à l'aménagement plus complexe. On verra qu'un texte du $\mathrm{XvI}^{\mathrm{e}}$ siècle en fournit sans doute le nom. Enfin, la sortie de la rue qui descend de la Madeleine, vers le sud-ouest semble encadrée par deux bâtiments identiques. Là encore la réponse viendra d'un texte, mais cette fois-ci du XVIII ${ }^{\mathrm{e}}$ siècle. En revanche la porte de la Madeleine est absente. Notons aussi que sur ce plan, si le fossé se raccorde bien à celui de la ville au nord, il ne le fait pas à l'ouest. À partir de sources archivistiques du XVIII ${ }^{\mathrm{e}}$ siècle, il sera montré plus loin que cette face était pourtant tout autant défendue que le reste de la ville. C'est que ce plan est très sélectif, ne montrant par exemple que très partiellement le château et ses fossés : son but n'était pas de décrire la ville pour les historiens à venir, mais de montrer les difficultés qu'éprouvaient alors les Pouancéens à se rendre à l'église paroissiale de Saint-Aubin et d'étayer la demande d'érection de la Madeleine en paroisse ${ }^{43}$. On note encore que les halles sont

41. Arch. dép. du Maine-et-Loire, 43 H/42.

42. Au XVIII ${ }^{\mathrm{e}}$ siècle, à Pouancé, on emploie souvent ce mot rejet pour désigner les importants talus bordant les fossés de ville, réalisés tout simplement avec les terres et les schistes extraits lors du creusement. C'est sans doute la raison qui en 1749 poussait le prieur Proust à se demander si dans l'acte de fondation du prieuré de la Madeleine de 1094, le mot dejecteria ne pouvait pas signifier fossé ou douve (Arch. dép. du Maine-etLoire, 43H1/6). Il faisait sans doute un rapprochement avec deiectio qui peut signifier déjection, et donc pourquoi pas rejet de fossé, comme on en voyait à son époque, à l'ouest du bourg de la Madeleine, dans les Prés Marais. L'étymologie n'est peut-être pas infondée; cependant, l'objectivité oblige à dire que la charte de 1094 ne contient pas le mot dejecteria mais vicum de inter vineas usque ad Degeteriam. (Arch. dép. du Maine-etLoire, $43 \mathrm{H1} / 3$ et 3 bis et transcription par Paul MARCHEGAY, Chartes angevines des $\mathrm{XI}^{\mathrm{e}}$ et $\mathrm{XII}^{\mathrm{e}}$ siècles, Bibliothèque de l'École des Chartes, t. 36, XX, 1875). La volonté du prieur de démontrer l'ancienneté des droits de son prieuré face aux empiètements seigneuriaux, peut expliquer sa tendance à solliciter, voire à sur-interpréter le texte.

43. Arch. dép. du Maine-et-Loire, C81, Érection de la paroisse de la Madeleine. 48 pièces, un plan et débris de sceaux. 
figurées, ainsi que l'église de la Madeleine, son grand placître et sa croix. Relevons encore que les fossés qui entourent la ville sont immédiatement doublés d'une ceinture de routes. On verra plus loin que celles-ci étaient installées sur les anciens talus ou " rejets " externes. Il en est de même pour le champ de foire, au sud, qui occupe aussi la partie haute de la vallée où est aujourd'hui la fontaine de Bretault. Un peu plus bas et à l'ouest, l'étang de Fonte Britelli (Bretault) du $\mathrm{xI}^{\mathrm{e}}$ siècle a disparu, mais la délimitation de 1760 citée plus haut, montre que son emplacement se voyait encore.

\section{Figure 5 - Plan de Pouancé de 1781 (AD Maine-et-Loire)}

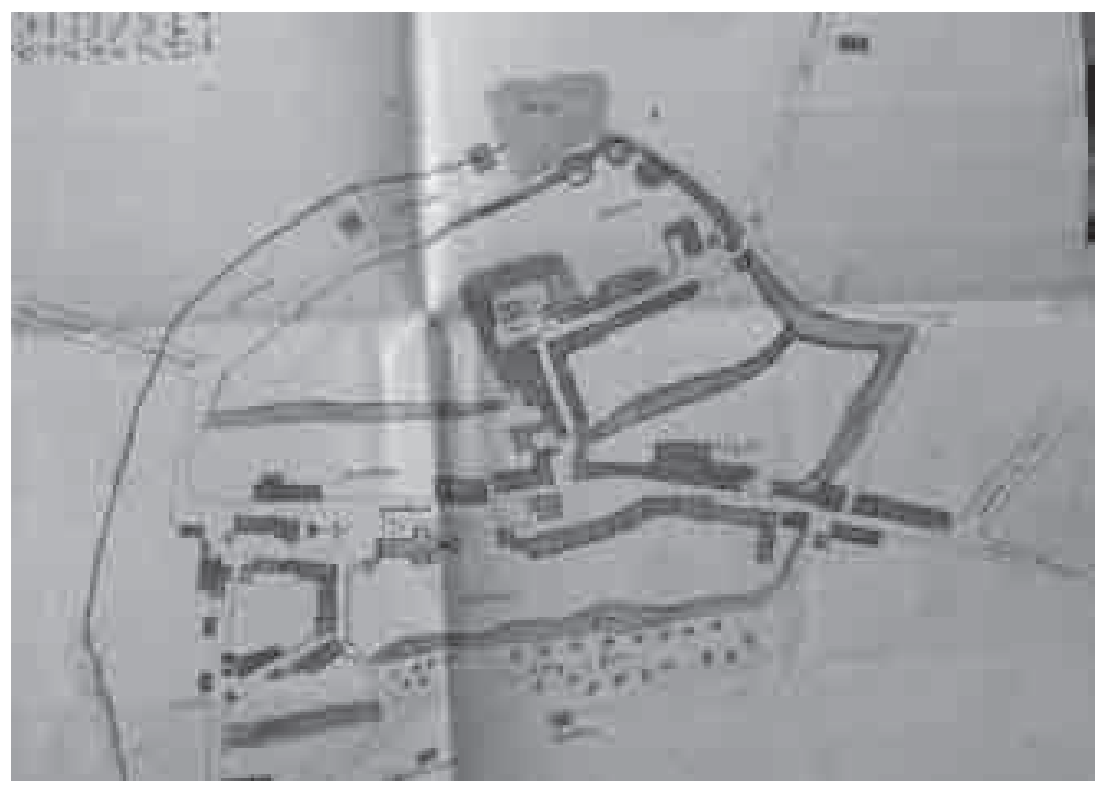

\section{Le plan retracé par $H$. Godivier}

Un second plan, retracé et publié par H. Godivier ${ }^{44}$, est daté des années $17 .$. (fig. 6). Il permet de visualiser l'emprise et les principales structures bâties de la ville et du château. Le levé peut être considéré comme spatialement fiable car il se superpose bien au cadastre napoléonien.

On y voit que le fossé de la ville est encore conservé sur presque toute la périphérie, spécialement au nord et à l'est où il figure avec sa largeur actuelle voisine de $20 \mathrm{~m}$. Au sud cependant, il est en cours de comblement et de colonisation par des habitations, ainsi que par le chemin de Pouancé à Châteaubriant. La muraille urbaine est complète, scandée par des tours

44. Arch. dép. du Maine-et-Loire, 11 Fi 5081, fonds iconographique. Plan tracé par H. Godivier qui était architecte à Pouancé, " d'après un croquis signé illisiblement ". 
Figure 6 - Plan de Pouancé de 17.. par Godivier (AD. Maine-et-Loire)

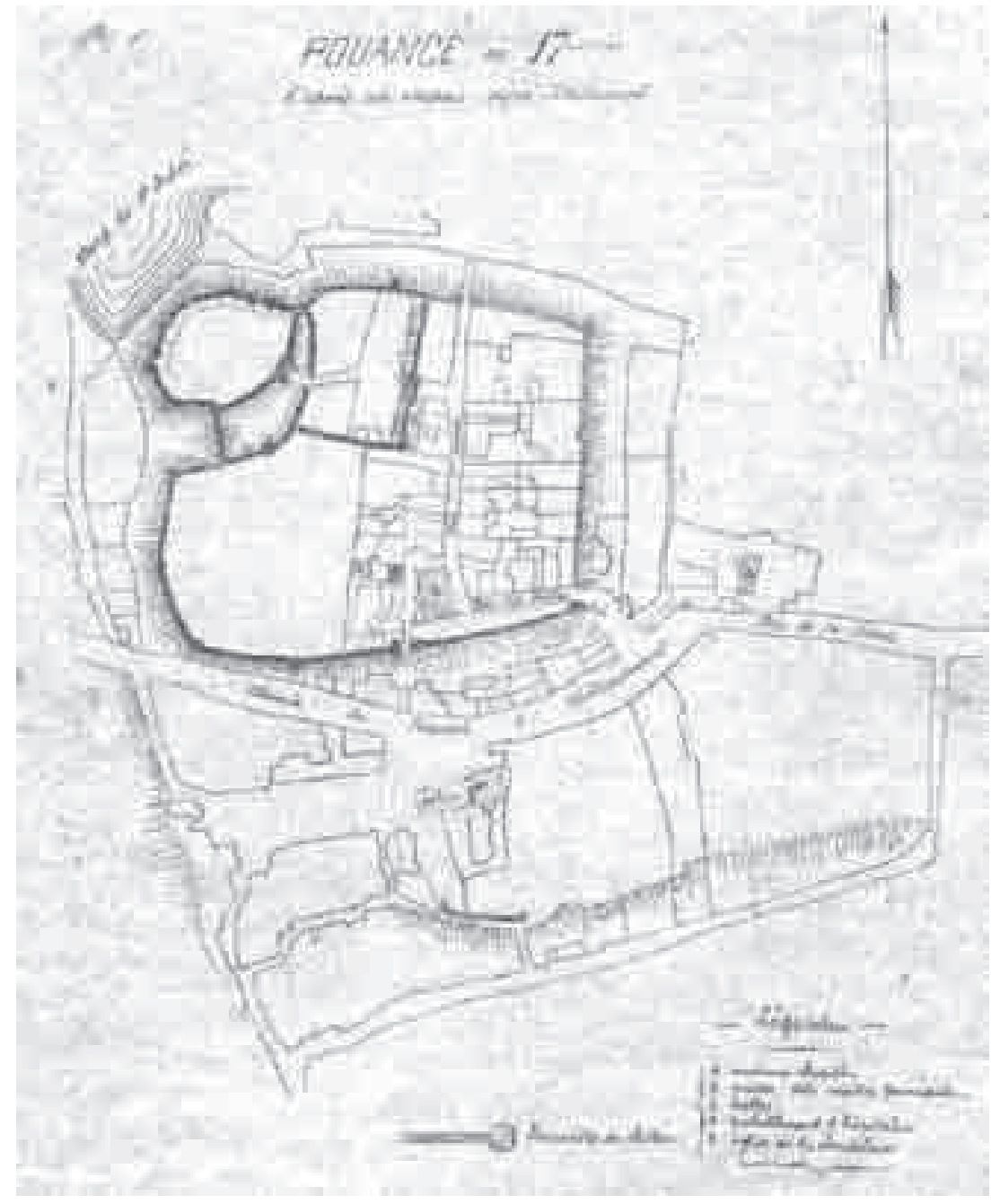

quadrangulaires ou circulaires, à des distances inégales, plus rapprochées du côté ouest et sud-ouest. On peut regretter qu'elles ne soient pas nommées, ce qui aurait permis des croisements avec les textes de l'époque. Trois portes sont bien visibles : au nord, c'est la porte Saint-Aubin, nommée portal Saint-Aubin aux siècles précédents, qui mène à la paroisse mère; présente sur le plan en 1833, elle sera détruite au cours du XIX ${ }^{\mathrm{e}}$ siècle; au sud, la porte de la Madeleine qui ouvre la ville close sur le bourg du même nom; elle ne figure plus sur le cadastre de 1833 et pourtant, elle existait encore en 
$1827^{45}$; enfin, au sud-est, la porte angevine ou de l'Horloge toujours visible en 2012. Comme on le voit aujourd'hui encore à cette dernière, ces portes sont dotées de deux tours et semble-t-il d'un seul passage mixte. Les halles anciennes sont bien figurées, non loin de la porte de la Madeleine; elles ne seront détruites et reconstruites qu'à l'extrême fin du XIX siècle À noter surtout le grand et mystérieux espace interne, non bâti, à l'ouest de la ville. Sa muraille comporte plusieurs tours dont une grosse à l'emplacement de la porte qu'on voit aujourd'hui au nord, ouvrant sur le fossé du château et sa poterne sud. Son relevé et son étude figurent dans le dernier chapitre.

Le bourg de la Madeleine est clairement cartographié. D'abord l'église prieurale au centre, dont on voit le chevet semi-circulaire (c'est l'église romane primitive qui sera rebâtie en 1859-60), et un ensemble quadrangulaire bâti contre le mur sud de la nef : ce sont les bâtiments prioraux dessinant peut-être l'ancien cloître. L'abrupt toujours visible aujourd'hui est bien figuré au sud par des hachures, moins nettement à l'ouest. Deux détails sont à souligner : d'une part un mur figuré au-dessus de l'abrupt sud, sous l'église, on verra qu'il en reste des traces; d'autre part un espace parcellaire allongé, exactement à l'endroit où le texte de 1760 indique la limite est du bourg prieural : c'est, selon nous, la partie est de l'ancien fossé, comblée à cette époque. Enfin l'hôpital est indiqué en D, mais le fossé qui le cerne sur le plan de 1781 n'est pas représenté.

\section{Lep lande 1833}

Le plan cadastral de 1833 (F2, Ville) (fig. 7) ne signale pas de changements majeurs, sauf pour la partie sud de l'enceinte urbaine où la porte de la Madeleine ne semble plus exister, et où les fossés sont presque totalement gagnés par des constructions, et donc remblayés. En revanche, les halles sont toujours présentes. Et l'on observe le même grand espace vide à l'ouest de la ville désigné comme quartier du château. L'ancienne porte qui le faisait communiquer avec le fossé du château, au-dessus de la poterne sud de ce dernier, n'est pas figurée, sans doute parce qu'elle a été découronnée, telle qu'on la voit aujourd'hui.

\section{La ville de Pouancé en 2011, des textes au terrain}

Seront présentées et analysées ici les édifices et structures qui apportent des éléments nouveaux. Elles concernent cinq lieux ou structures.

\footnotetext{
45. Arch. dép. du Maine-et-Loire, 5 E 40/90 (24-11-1827), acte de vente portant sur « un emplacement de terrain au-dessus des deux tours du Port Ubi, actuellement en jardin, et où étaient autrefois les prisons de Pouancé, joignant [...]enfin du Nord rüe des Halles ". On ne connaît pas d'autre mention des tours du Port Ubi, mais l'indication des halles au nord et des prisons dans ces tours permettent d'affirmer qu'il s'agit de la porte de la Madeleine.
} 
Figure 7 - Plan cadastral de la ville de Pouancé, 1833. (Mairie Pouancé)

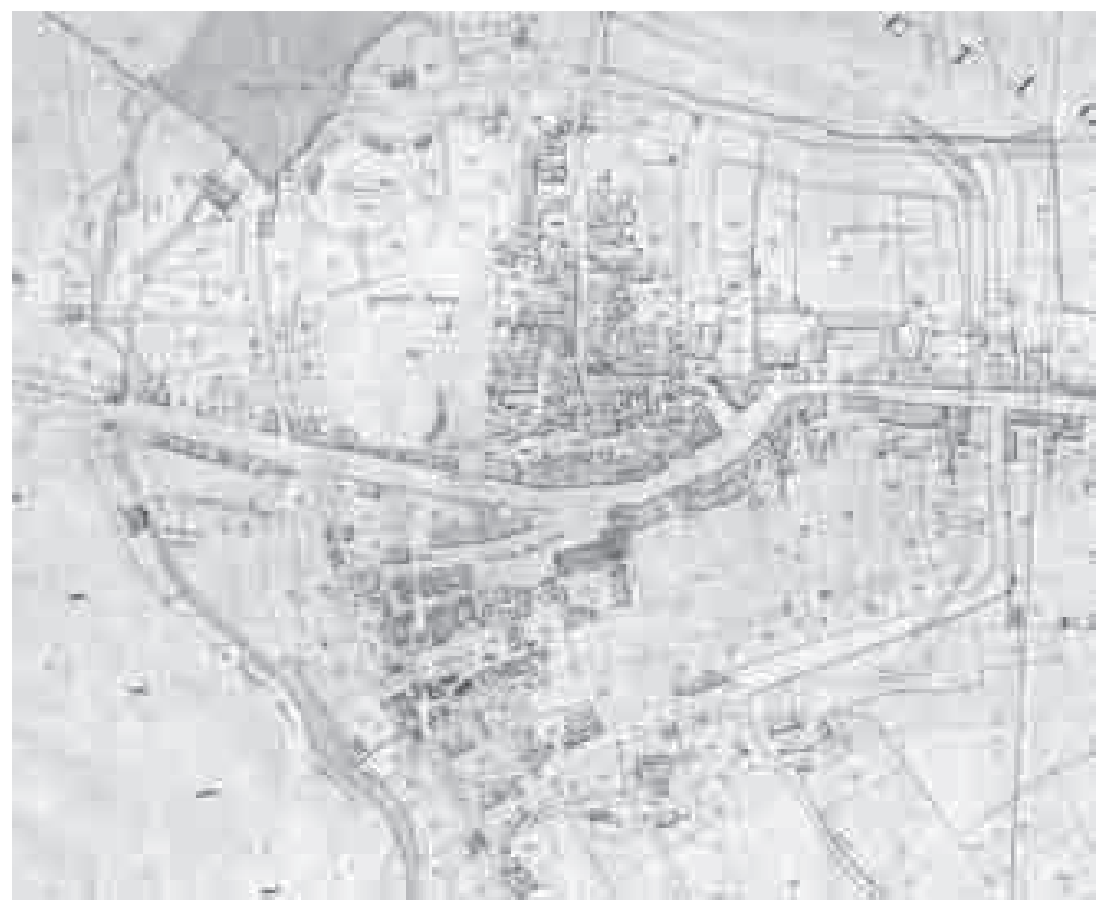

\section{Lac hapelleS aint-Pierre}

Mentionnée en 1263 comme ecclesie sancti Petri de Poencé ${ }^{46}$, elle n'apparaît que rarement par la suite, et seulement comme chapelle. Est-ce à dire qu'on ait eu alors la volonté de l'ériger en église paroissiale? Ses restes se trouvent dans la ville, mais tout contre le mur qui sépare la partie construite du " terrain du patronage ". Il en reste les deux murs gouttereaux avec des contreforts plats et une demi-fenêtre trilobée au nord, en grès roussard et qu'on aurait tendance à attribuer au XIII ${ }^{\mathrm{e}}$ siècle On observe aussi sur son côté sud, à l'est du mur de la nef, mais en léger retrait, un fragment de mur courbe contenant encore la moitié d'une étroite meurtrière. Il s'agit de l'ultime reste d'un chevet semi-circulaire abattu et intégré à un mur rectiligne.

En 1721, il est dit que « la porte de ladite chapelle ouvre sur le jardin du château dudit seigneur comme elle avait toujours été ${ }^{47}$ ". Mais en 1785 , elle n'est plus qu' une antique chapelle dont on peut faire écurie et magasin

46. Cartulaire des sires de Rays, publié par BlANCHARD René, Archives historiques du Poitou, XXX, 1889, p.113.

47. Arch. dép. du Maine-et-Loire, 5 E 40/56. 
à fourrage ${ }^{48}$ ". Sur le plan de 1833, elle figure en F2, 236, accostée de deux petits édifices postérieurs, et aujourd'hui, elle est depuis assez longtemps à usage d'habitation. Mais à l'intérieur, nous avons pu y observer une belle charpente du $\mathrm{xv}^{\mathrm{e}}$ siècle avec traces de lambris sur les chevrons formant ferme et un ou deux $\mathrm{m}^{2}$ de peintures murales en haut du mur nord. Trop éloignée du château même pour être considérée comme chapelle castrale - cette dernière a été cherchée en vain par T. Géhant lors de ses fouilles du château - nous y verrions plutôt une tentative consciente ou non d'église paroissiale dans l'agglomération castrale, au cours du XIII ${ }^{\mathrm{e}}$ siècle. Le développement important du prieuré de Marmoutier au centre de son bourg contigu à celui de la ville, avec la présence exceptionnelle de quatre moines indiquée dans la charte des environs de 1220, pourrait avoir bloqué l'évolution ultérieure. Ce genre de tentative-tâtonnement, au cœur d'un bourg castral est un phénomène classique fin $\mathrm{XII}^{\mathrm{e}}$ et au XIII ${ }^{\mathrm{e}}$ siècle. Il illustre le processus de structuration de la ville et traduit le développement démographique et urbain.

\section{Les fossés et murs de ville au nord, à l'ouest et au sud}

\section{Lesfossé sc onservés}

Bien représentés sur les plans du XVIII et sur celui de 1833, ils sont aujourd'hui toujours visibles au nord et à l'est. Creusés dans le rocher, constitué ici de schiste, leurs dimensions sont encore impressionnantes : profondeur voisine de 4 à $5 \mathrm{~m}$ et largeur 15 à $20 \mathrm{~m}$. Leur fond aujourd'hui occupé par d'anciens jardins ou des cours, est pratiquement plat. Ils présentent donc un profil en auge. Depuis l'ancienne porte Saint-Aubin jusqu'à la porte de l'Horloge, soit les parcelles F2, 255 et 281 de 1833, ils sont aujourd'hui bordés intérieurement par des murs plus ou moins continus. Leur hauteur va de 2 à $3 \mathrm{~m}$ et leur épaisseur inégale de 2 à 2,20 m, ces mesures prises au fond des jardins de $\mathrm{M}^{\mathrm{me}}$ Planchenault (1833, F2, 249) et de M. Metzger (1833 : F2, 261), rue Saint-Aubin. En ce dernier cas, le mur porte à son revers extérieur un sentier suspendu à 3-4 m au-dessus du fond du fossé, et qui peut avoir été un sentier de ronde destiné aussi à l'entretien de la muraille. Souvent remaniés, parfois ouverts par une porte postérieure, ces murs ne sont pas datables mais ils correspondent à l'emplacement de la muraille portée au plan du XVIII ${ }^{\mathrm{e}}$ siècle recopié par Godivier. On en a confirmation sur la face nord de la tour nord de la porte de l'Horloge : celle-ci, en forme de fer à cheval, conserve une porte obturée visible de ce côté à environ $5 \mathrm{~m}$ de hauteur; verticalement, sous cette porte se voit un arrachement de mur encore en saillie, épais d'environ $1 \mathrm{~m}$, et au-dessus, mais un peu à l'extérieur et contre le jambage externe de la porte, deux pierres encore en saillie qui semblent être le reste d'un parapet. Ces détails

48. Arch. dép. de l'Indre-et-Loire, C 75 (9 juin 1785) : Où loger la maréchaussée de Pouancé? 
montrent qu'au moins en cet endroit existait un chemin de ronde auquel on accédait par la porte à l'étage de la tour.

\section{Les fossés de l'hôpital ou faubourg de la Rouërie}

Nous parlerons assez peu de ces fossés qui ceignaient l'hôpital sur le plan de 1781, et qu'on distingue encore sur celui de 1833 (F2, 309 au nord et F2 373, 374, 384, 385, 392 au sud), autour du "quartier de l'hospice ". Un plan de 1838 (fig. 8) montre qu'ils existaient encore au nord et à l'est de l'hôpital, larges, plantés d'arbres et toujours en creux, au moins partiellement, car on y distingue un grand bassin rectangulaire et une sorte de fontaine. Ils sont désignés comme " anciens fossés de la ville ${ }^{49}$ ". Il n'est pas douteux qu'ils aient été doublés d'un mur intérieur : en 1832 on évoque " quelques débris de murs et des apparences d'anciens fossés indiquant la première enceinte qui paraît avoir régné du côté de Segré, vers l'endroit où aboutit la route de Laval ${ }^{50}$ "; et en 1971, lors de terrassements, on a pu observer sur huit mètres de longueur, un mur de pierre angulaire haut de $2 \mathrm{~m}$, en appareil de schiste, semblable à celui du "Vieux Château ${ }^{51}$ " : il s'agit sans doute d'un reste du franchissement du fossé à la sortie est, par le grand chemin de Segré et Angers, pour tout dire d'une porte. Or, un texte de 1547 contient l'intrigante mention d'un portal de Vergone, jamais retrouvé dans d'autres sources ${ }^{52}$. Où peut-on alors le situer? Il existe déjà une autre ouverture de ville vers Vergonnes et Segré. C'est la porte angevine, toujours visible aujourd'hui, et qui ouvrait la première enceinte, celle des premiers bourgs. Elle figure dès 1406 dans les devoirs de garde d'un vassal du duc d'Alençon, déjà nommée porte angevine ${ }^{53}$. C'est toujours le cas sous l'Ancien Régime et jusqu'à aujourd'hui, où elle est aussi désignée comme porte de l'Horloge. De sorte qu'on ne peut se tromper : le portal de Vergone de 1547 ne peut que désigner l'ouverture vers l'est du quartier de l'hopital. Depuis longtemps abattus, comblés et occupés par des boulevards, les murs et les fossés de ce quartier de l'hospice ne se voient plus qu'en bas du boulevard de la Marne, en face du n ${ }^{\circ} 10$ : en cet endroit, sur

49. Arch. dép. du Maine-et-Loire, X 123, 1838.

50. Godivier, Henri, Histoire de Pouancé et des environs, Poirier, Mayenne, 1906, p. 147. Citation du marquis de Preaulx.

51. L'EIL de Boeuf (= Louis BessiÈre), "Pouancé souterrain ", Le Courrier de l'Ouest, 26 avril 1971.

52. Arch. dép. du Maine-et-Loire, E 1133, Armaillé, livre 2, p. 326 vº 20 février 1547, aveu de Pierre Percault, seigneur de Combrée à Anne d'Alençon, marquise de Montferrat, baronne de Pouancé et de La Guyerche : " [...] vous doy huyt jours et huyt nuits de garde $[\ldots]$ envotre dicte ville de Pouencé, entre le portal de Vergonne et la tour de Monteclerc...".

53. Arch. dép. du Maine-et-Loire, E 1133, Armaillé, livre 2, p. 383 v 10 janvier 1406, aveu de Jean d'Armaillé, seigneur du Bois-Geslin au comte d'Alençon et du Perche, seigneur de Pouancé : «[...] vous dois quinze jours et quinze nuits de garde au bessoin et deffance de votre ditte ville de Poüancé [...] à estre fait la ditte garde entre la porte angevine et la tour de derrière l'hôtel Hurlault..." ". 
$40 \mathrm{~m}$ de longueur, subsiste un beau mur de plaquettes de schiste au fruit très marqué, haut de $3,50 \mathrm{~m}$ avec à son pied un large espace où se trouvait naguère le Petit champ de Foire (1833, F2, 392 : place). Sur le plan de 1781, ce fossé du quartier de l'hôpital est figuré en bleu (en eau?) avec une largeur identique aux autres fossés de Pouancé, mais sans mur. D’ailleurs, dans une description de Pouancé en $1701^{54}$, ces murs ne sont pas décrits, soit qu'ils aient déjà été détruits, soit qu'ils aient été trop peu importants pour mériter être signalés. Comme cela a été dit plus haut pour le fossé de la ville, on ne peut pas ne pas poser l'hypothèse d'un creusement simultané, $\mathrm{au} \mathrm{XV}$ siècle, lors de l'avènement de l'artillerie et de la montée de l'appétence française pour la Bretagne. Il semble bien que ce soit à cette époque de la fin du Moyen Âge, que toutes les défenses du château et de la ville aient été repensées. Ici, ce serait une extension rapide à mettre en œuvre et à moindres frais, que l'on aurait réalisée du côté de l'est, le plus plat et donc le moins bien défendu de la ville. Là encore le creusement de ces fossés s'accompagnait de talus extérieurs, les "rejets" : on en a une première preuve sur le plan de 1833, à l'intérieur de l'espace du « quartier de l'hospice ", sous la forme de parcelles allongées caractéristiques, placées contre le fossé est de la ville, et de même largeur que celui-ci (F2, 282, $283,284,285)$. Un rapport d'accident de 1840 en fournit une seconde : on y apprend que « la route stratégique de cette ville (Pouancé) à Ancenis, se trouve vis-à-vis la douve de la Charité et de l'hospice " et que cette dernière " est en contre bas de la route d'environ quatre mètres ". Pour cette raison, " une voiture Bertin contenant trois dames, six messieurs et un enfant [...] a été entraînée par un des chevaux qui a été effrayé, dans cette douve " et " en tombant a fait un tour sur elle-même ". Aussi l'élu demande-t-il la construction d'un parapet ${ }^{55}$. La description montre clairement que cette route avait été installée sur le talus externe de la douve : après aplanissement du sommet, celui-ci, offrait en effet une bonne assise de terre et de schiste, stable et bien drainée. Ce schéma d'installation de " boulevards périphériques " sur les rejets s'observe à l'identique, sur les plans de 1781 et 1833, au nord et au sud du quartier de l'hôpital.

Si sur le plan de 1781 l'hôpital se voit à l'intérieur de ces fossés, nous pensons que la présence du premier est sans rapport avec le creusement des seconds. C'est en effet seulement au début du XVIII ${ }^{\mathrm{e}}$ siècle qu'a été créé cet établissement : premiers projets en 1690, achat du terrain en 1703 et lettres patentes du roi en $1706^{56}$. À une telle date, on ne fortifie nulle part les hôpitaux de tels fossés. Et si cela avait été le cas, les nombreux textes de cette époque en auraient fait mention. Grâce à l'acte de vente de 1703 , on sait que le terrain où il fut installé portait alors des noms qui

54. Arch. dép. du Maine-et-Loire, 43 H, (1701), prise de possession du prieuré de Pouancé.

55. Arch. dép. du Maine-et-Loire, 5 Z 645, (19 août 1840), Lettre de l'adjoint au maire de Pouancé, J. Leclerc, au sous-préfet de Segré.

56. NEAU André, Sur les chemins de l'Histoire..., p. 160-163. 
Figure 8 - Plan de 1838 : fossés de l'hôpital (AD Maine-et-Loire)

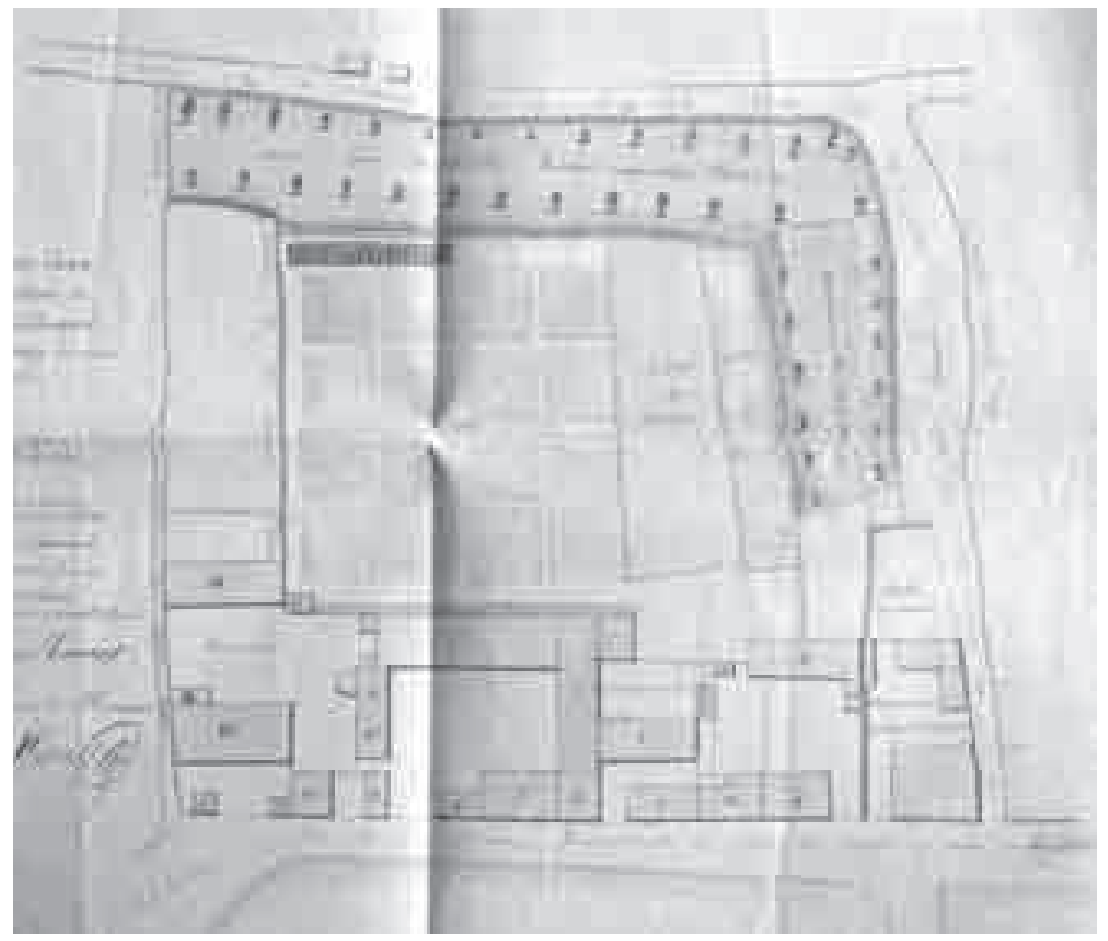

peuvent éveiller l'attention " une grande maison, cour, jardin et appartenances appelé le Grand Dauphin scises au faubourg de la Rouayrie de Pouancé, paroisse de Saint-Aubin ${ }^{57}$ ". Ce faubourg de la Rouayrie apparaît une autre fois dans nos sources, à l'occasion de la délimitation du fief de la Madeleine en 1760, bien localisé dans la même direction, mais orthographié Houayrie $^{58}$. On ne sait donc pas quelle est la bonne dénomination. Quant à la maison du Grand Dauphin on pourrait penser qu'elle fut ainsi nommée, en raison d'un lien direct avec un fils de roi : celui de Louis XIV, mort en 1711, mais aussi ceux des siècles précédents, qui devinrent Charles V, VI, VII, VIII et Louis XI. Plus prosaïquement, on sait aussi que nombre d'auberges ont porté de telles dénominations publicitaires en forme de jeux-de-mots (Lion d'Or, Chapeau rouge, Boule d'Or...). Si c'en était une, elle se serait alors trouvée en bonne situation, proche du portal de Vergonne, à la sortie de la ville, en direction d'Angers.

57. Arch. dép. du Maine-et-Loire, 5 E (13-11-1703). Cf aussi ElAin-LACRoIX, Jules, Notice historique sur l'hôpital de Pouancé, Angers, 1888, p. 5 : «En 1703, Mme Marguerite-Françoise de Thierry Langeraye installa l'hôpital dans les bâtiments et terrains dits Le Dauphin, situés à Pouancé, faubourg de la Rouërie [...] pour la somme de 1200 livres. »

58. Cf. note 39 . 
Le portail craonnois ou la porte oubliée (fig. 9)

Figure 9 - Relevé du probable portail craonnois (J.-C. Meuret)

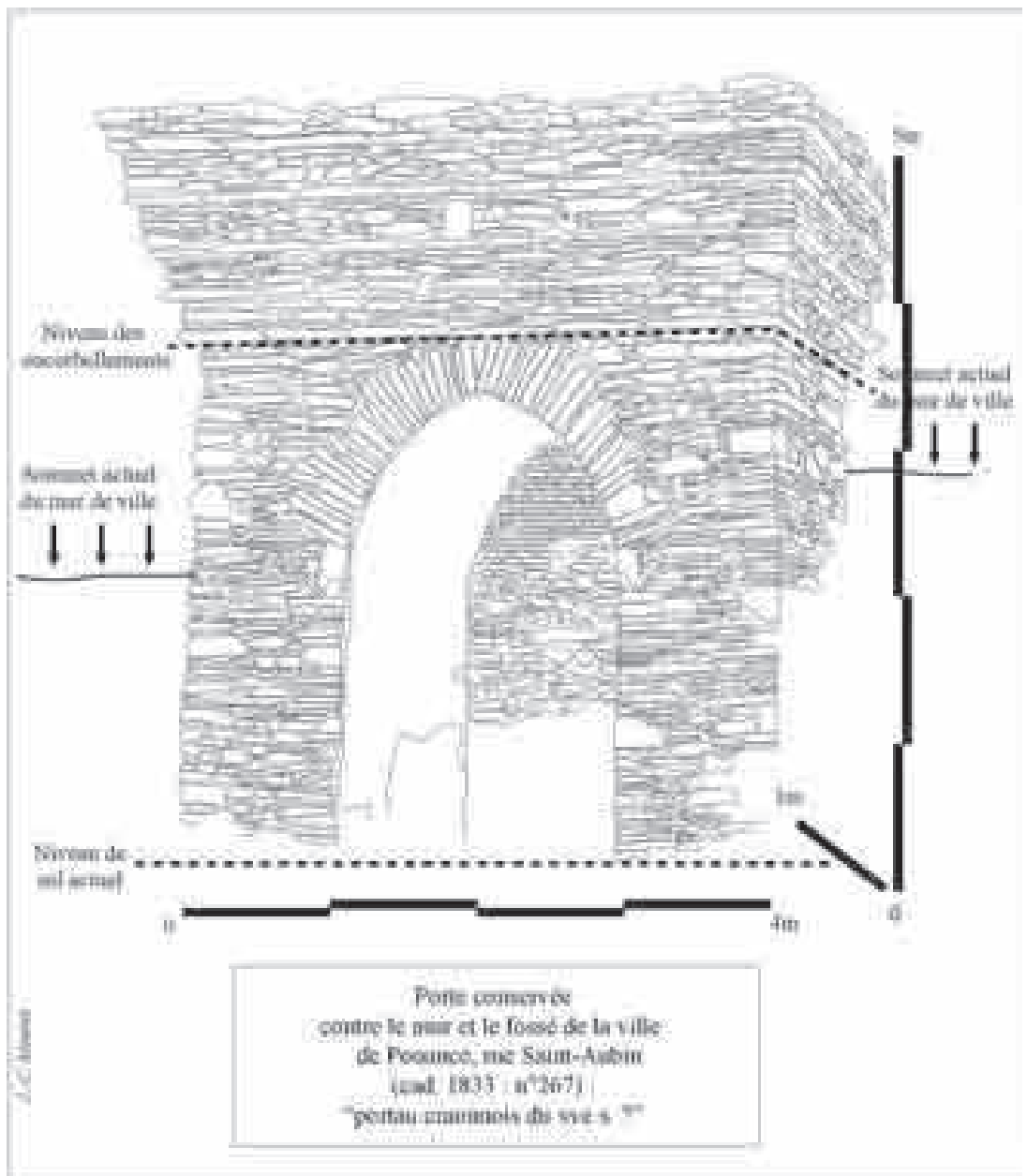

Il ne subsiste plus de traces de la tour circulaire portée à l'angle nordest du fossé sur le plan du XVIII ${ }^{\mathrm{e}}$ siècle. En revanche, dans la parcelle 267, se voit encore un curieux édifice en élévation. Il est constitué d'un mur épais de plus de $1 \mathrm{~m}$; sa façade l'ouest, donc vers l'intérieur de la ville est large de $4 \mathrm{~m}$ et haute de $5 \mathrm{~m}$. Son sommet est constitué d'une succession de cinq encorbellements de schiste formant une sorte de gênoise sur $1 \mathrm{~m}$ de hauteur. Et sur celle-ci est fixé un garde-fou de fer forgé. Au milieu de cette façade, ouvrant au niveau du jardin, une porte large de 1,75 m, en arc brisé haut de $3 \mathrm{~m}$ au-dessus du sol actuel, à claveaux de schiste, matériau qui 
constitue le reste de l'édifice. La face est du massif de cette porte s'aligne sur les restes du mur de ville. Cependant le bouchage de l'ouverture ellemême n'en est pas contemporain parce qu'il est, au moins dans sa partie haute, constitué de briques ou grosses tomettes. L'interprétation sur le seul terrain en est difficile. D'une part, certains observations incitent à quelque méfiance : le couronnement en encorbellement avec le garde fou de fer forgé peut paraître récent, $\mathrm{XVIII}^{\mathrm{e}}$, sinon $\mathrm{XIX}^{\mathrm{e}}$ siècle, tout comme le sommet du comblement de la porte en tomettes. Et puis, l'observation du mur actuel qui somme le fossé, au niveau de cette pseudo-porte, et derrière elle, ne permet de déceler aucune trace de piédroit de porte, reprise ou arrachement. On y observe un appareil continu de petites plaquettes de schiste, sans aucun liaisonnement entre le mur de ville et la porte-arc : celle-ci n'est qu'appliquée. De plus, s'il s'agissait bien d'une porte ou poterne de ville, on devrait trouver dans son axe, à la fois de l'autre côté du fossé vers l'est, ainsi que vers la ville en direction de l'ouest, la trace d'une rue ou une ruelle. Mais il n'en est rien, si ce n'est un étroit passage entre la maison de M. Metzger et celle des ses voisins au sud. Enfin la tradition rapportée par l'actuel propriétaire de cette problématique construction, serait qu'au XIX ${ }^{\mathrm{e}}$ siècle, le notaire qui vivait là aimait recevoir ses amis au sommet de l'édifice et qu'ils se livraient là à des parties de cartes tout en buvant du Porto. De là à penser à une "folie ", à une fausse ruine construite par un notable, il n'y avait qu'un pas. Cependant, plusieurs éléments nous amènent à conclure à son authenticité et à sa relative ancienneté : d'abord sa forte ressemblance générale par sa forme, son arc, ses dimensions, avec la porte de ville obturée qui sera présentée au dernier chapitre comme " ancienne "; ensuite, comme pour cette dernière, un emploi quasi exclusif des plaquettes de schiste et l'absence totale de granit, matériau qui apparaît au contraire au château dans des parties plus " récentes " (logis, cheminée, fenêtre, poternes, porte de la basse-cour...); puis le fait que cette porte est à peu près alignée sur les issues principales du château (pont dormant de la haute cour et porte de la basse-cour près du Grenier à sel); enfin sa présence très nette sur le plan $\mathrm{du}_{\mathrm{XVIII}}^{\mathrm{e}}$ siècle recopié par Godivier et sur un plan de voirie de $1836^{59}$.

C'est en tout cas un édifice qui mériterait étude encore plus approfondie pour écarter avec encore plus de certitude l'hypothèse d'une de ces "fabriques " construites à partir du XVIII ${ }^{\mathrm{e}}$ pour orner les parcs et jardins, et mieux asseoir celle d'une vraie porte médiévale. Si cette dernière hypothèse est fondée, cela signifie que le mur et le fossé de la ville qui se trouvent derrière, lui sont postérieurs. Et dans ce cas cela amènerait à penser que ce large fossé a été élargi, recreusé et le mur reconstruit à la fin du Moyen Âge, au XV ${ }^{\mathrm{e}}$ siècle par exemple. En même temps pourrait avoir été creusé le fossé autour de l'hôpital, celui qu'on voit sur le plan de 1781 et qui apparaît d'ailleurs de même largeur que ceux de la ville sur les autres plans. Ces terrassements auraient alors été faits en même

59. Arch. dép. du Maine-et-Loire, 7 S 2, 1836. 
temps qu'on réalisait d'importants travaux de mise en défense au château et aussi, comme on va le voir, à l'ouest de la ville. Ce serait alors à cette occasion, que la porte aurait été condamnée et scellée, tout comme la rue ou la ruelle qu'elle contrôlait, que le mur de ville aurait été reconstruit à cet endroit, et qu'ainsi aurait disparu toute trace de piédroit du côté du fossé. Et puis, le moment est venu ici de rappeler qu'il existe dans l'aveu pré-cité de 1408 (et répété en 1445) la mention d'un "porteau ou portau craonnois ", une porte de Craon. Or ce portail - qu'il faut comprendre dans le sens de porte de ville comme pour le portail de Saint-Aubin cité par deux fois - ne pouvait qu'ouvrir vers cet endroit, soit à peu près en direction de la ville de Craon, vers l'est/nord-est. On sait encore que presque toutes les portes des villes médiévales étaient désignées par le nom de la ville vers laquelle elles ouvraient. Autant de considérations qui nous font, en l'état des connaissances, fortement pencher pour l'hypothèse d'une réelle porte de ville médiévale, conservée, puis réaménagée à son sommet à des fins d'agrément, au XVIII ${ }^{\mathrm{e}}$ ou XIX ${ }^{\mathrm{e}}$ siècle.

Pour en finir avec ce chapitre du fossé est du bourg castral, on doit rapidement évoquer à nouveau la porte de l'Horloge qui en marque la limite sud-est. Récemment, celle-ci aurait pu être acquise par la collectivité; il n'en a rien été et ce fut une occasion manquée de procéder à une étude sérieuse de ce bâtiment, souvent présenté comme l'emblème médiéval de la ville. Lors d'une visite impromptue en 2010, alors que des travaux d'aménagement y avaient lieu, nous avons pu constater qu'il s'agit d'un édifice peu lisible à cause de multiples transformations anciennes ou récentes. Toutes les ouvertures actuelles ont été transformées dans les derniers siècles et on ne voit plus (ou pas) trace d'arbalètrières et encore moins de bouches à feu. Cependant divers indices, en particulier visibles au dernier niveau de la tour sud (nous n'avons pas visité la tour nord), montrent d'importantes modifications de la structure et du plan de celle-ci. Là encore sans doute à l'occasion des mêmes travaux du $\mathrm{xv}^{\mathrm{e}}$ siècle.

\section{Troisièmeé lémentn ouveau etm ajeur : le bourg de la Madeleine, ses fossés, ses murs}

\section{La face sud du bourg}

Précisons tout d'abord que c'est sur une erreur de lecture de la charte de 1094 que nous fondions l'existence d'une clôture autour de ce bourg monastique ${ }^{60}$. Cependant, depuis, la visite approfondie des murs et jardins a permis de constater que celle-ci a réellement existé sous la forme de murs et fossés. Et parallèlement, plusieurs sources écrites du XVIII ${ }^{\mathrm{e}}$ siècle en ont fourni confirmation. La plus précoce date de 1701, on la doit à un prêtre venu prendre possession du prieuré de la Madeleine; elle mérite

60. Meuret, Jean-Claude, Peuplement, pouvoir et paysage..., p. 430 et p. 437. Dans la charte $43 \mathrm{H1} / 3$ bis, on ne doit pas lire sepes, donc haie ou clôture, mais sepe, l'adverbe souvent. 
être citée, pour sa valeur descriptive et archéologique : "Cette magnifique ville [Pouancé] n'a de dehors basty que d'un seul costé, qui est un petit faux-bourg fortifié seulement d'un fossé profond et large. Dans ce fauxbourg est basty le prieuré de la Magdelaine et devant l'église est une place assez raisonnable ${ }^{61} \ldots$. Ce bourg prieural se trouve installé au sud du même petit plateau qui porte le château et la ville, entre 75 et $85 \mathrm{~m}$ d'altitude. Il surplombe d'environ $10 \mathrm{~m}$ l'actuel quartier du Champ de foire installé dans une petite vallée est-ouest où se trouve la fontaine de Bretault et qui s'écoule vers la Verzée. Cet abrupt forme une ligne est-ouest. Dans sa partie centrale et encore plus à l'ouest, celui-ci a visiblement été accentué par la construction de murs terrasses aujourd'hui très hétérogènes, mais d'aspect " ancien ", contenant de nombreux remplois de grès roussard. Aujourd'hui encore, le pied de cet abrupt aménagé est occupé au sud par des jardins larges de 15-20 m et qu'on nomme " les fossés " comme sur le plan de 1781 . Sur le plan de 1833, ils occupent une bande continue (F2 : 384, 392, 399, 405, 406, 407, 412, 459). Dans un de ces jardins, en F2, 412, au 46 bd du champ de Foire, $M^{\text {lle }}$ Hunault a trouvé en 2009 un boulet de fer de 1,380 kg et de $70 \mathrm{~mm}$ de diamêtre. Selon N. Faucherre, " cela peut être un projectile de fauconneau ou de couleuvrine bâtarde. Il y aurait même moyen de vérifier, avec le poids et le calibre, si c'est de l'artillerie de Louis XI ".

Sur toute cette longueur sud, le mur est le plus souvent conservé, impossible à dater bien sûr, souvent remanié à plusieurs reprises, avec des escaliers conservés ou non, mais très net et surplombant de 6-7 m le "fossé ", moins quand on remonte vers l'est. La partie la plus visible se voit depuis le boulevard du champ de foire, au fond du jardin du n ${ }^{\circ} 22$ (F2 : 412), presque toujours montée petites plaquettes de schiste, avec un fruit marqué. On y voit des reprises modernes en pierre, ainsi qu'en béton. On observe aussi des traces de contreforts, parfois arrachés, mais reconnaissables à un remplissage différent remplaçant l'arrachement et parfois à des blocs de pierre (grès, voire granit) plus gros, restes des chaînages de ces contreforts.

Ce mur sud du bourg de la Madeleine surplombe non seulement les « fossés ", mais aussi la petite vallée de Bretault fortement remblayée à l'époque moderne pour y installer le champ de foire, et où passe aujourd'hui le boulevard du même nom. La fontaine de Bretault, portée au cadastre de 1833 (F2 : 461) y est toujours visible et en eau, à quelques mètres à l'ouest de la ferme de Bretault, au niveau du 11 bis bd du champ de Foire. Un peu plus bas en aval, au fond de cette même petite vallée, au $\mathrm{n}^{\circ} 19 \mathrm{du}$ bd du champ de Foire $(\mathrm{F} 2,472)$, on peut voir à $3 \mathrm{~m}$ sous le parapet du boulevard, un trou d'eau - un ancien lavoir - lui aussi en eau. Entre les deux, une maison des années 1970-80, implantée près du fond de la petite vallée, n'a pu être construite qu'après forage et coulée de pieux de béton de $6 \mathrm{~m}$, signe de la présence d'un très puissant comblement. Enfin, le bas du boulevard du champ de Foire et les maisons et jardins qui s'y trouvent, passe et se

61. Arch. dép. du Maine-et-Loire, 43 H (1701), prise de possession du prieuré de Pouancé. 
trouvent sur un bourrelet de terre d'au moins une dizaine de mètres de largeur, léger, mais net, qui barre la petite vallée du nord au sud, à hauteur des $\mathrm{n}^{\circ} 20$ et 50 du même boulevard (F2 : 448-449, 473). Tous ces indices de terrain réunis permettent d'affirmer que l'étang de Fonte Britelli de l'acte de 1094 se trouvait là, le bourrelet encore visible constituant probablement l'ultime reste de sa chaussée; le boulevard, les jardins, en remontant vers l'est jusqu'à Bretault et peut-être jusqu'au début champ de Foire occupent l'emplacement de l'étang asséché et fortement remblayé. Le procès-verbal de délimitation du fief de la Madeleine cité plus haut a apporté pleine confirmation de toutes ces observations puisqu'il cite à cet endroit l'ancien lit de l'étang de Bretault. Quant à l'origine du comblement de ce dernier, un arrêté municipal de 1811 prouve que les édiles et les habitants de Pouancé y ont fortement contribué ${ }^{62}$.

\section{La face ouest du bourg de la Madeleine}

Là le mur est moins bien conservé. Il semble que son angle sud se trouvait dans le jardin du 50 bd du champ de Foire, en bas du boulevard de ce même Champ de Foire. À cet endroit, dans un jardin, le propriétaire nous a montré l'arrachement correspondant à un escalier de pierre ancien qui permettait de monter au sommet du mur, soit au niveau du bourg de la Madeleine. En continuant vers le nord, au-dessus du boulevard d'Ancenis, se voit une carrière de schiste dont le front vertical atteint environ $5 \mathrm{~m}$ et qui a coupé un ancien mur épais et haut qui ne peut qu'être celui du bourg de la Madeleine. Ce même mur du front ouest se voit bien aux 5 et 7 de ce boulevard d'Ancenis, à 15-20 m en retrait, posé sur un front rocheux. Il atteint 7-8 $\mathrm{m}$ de hauteur et est parallèle à la rue de l'ancien hôpital. Cet abrupt rocheux, ainsi que le mur qui le surmonte, est coupé par trois rues qui descendent de la place de la Madeleine : la rue du Roquet, la rue du Chemin de Ronde (et non le Chemin de Ronde), et la rue de l'Ancien Hôpital. Les points où ces trois rues très pentues coupent la ligne du mur sont marqués par un net bombement qui paraît fossiliser l'assise d'une muraille. C'est dans ce secteur ouest du bourg de la Madeleine qu'est mentionné le 15 septembre 1738 " un vestige de tour à l'entrée du faubourg Ridard de cette ville, sur le grand chemin qui conduit en la ville d'Angers, du côté main droite en entrant en cette ville, couverte de genêt où le nommé Soyer, maréchal-ferrant a sa boutique ". Au dit Soyer a été " concédé et afféagé ledit vestige de tour, même six pieds de plus que son étendue à prendre du côté des fossés vers orient ${ }^{63}$ ". La description ne permet pas de localiser cette tour

62. Conseil municipal de Pouancé du 6 mai 1811 : "L'administration considérant que le champ de foire est trop ajusté, arrête que la douve du bas du jardin du presbytère et annexe de cette propriété fera partie dorénavant dudit champ de foire et que pour le mettre au niveau, tous les habitants de cette commune seront contraints d'y conduire leurs vidanges."

63. Arch. dép. du Maine-et-Loire, 5 E 40/34. Aveu rendu à $\mathrm{M}^{\mathrm{me}}$ la duchesse d'Alincourt, tutrice honoraire dudit seigneur marquis de Villeroy, son fils mineur. 
et cette entrée avec exactitude; cependant, il semble qu'elles se situaient à l'angle sud-ouest du bourg de la Madeleine, là où la tradition et un plan situent le faubourg Ridard et sa rue ${ }^{64}$ : en sortant par cette porte, vers le sud-ouest, on prenait le chemin d'Ancenis, en y entrant et en montant vers la Madeleine, à main droite, on se dirigeait bien vers Angers. En l'absence de tout vestige conservé, c'est une première et précieuse mention. De plus, au pied de ce mur ouest, sous l'actuel boulevard d'Ancenis, le même aveu mentionne "les fossés du faubourg de la Madeleine ". Attestation d'une tour, de fossés, sans doute, mais unique, ce qui doit inciter à la prudence. Heureusement le filtrage des archives nous a fourni d'autres preuves, et beaucoup plus détaillées. Ainsi, en 1779, près « la grande rue du faubourg Ridard ", donc au sud-ouest du bourg de la Madeleine, le prieur jouit entre autres, d' " une petite portion de douve plantée de noyers au bas dudit jardin $^{65}$ ". En 1784, un conflit de propriétés s'élève à propos de jardins, passages, lâchers d'eau des moulins, situés dans le Pré Marais, ce secteur situé au pied ouest de la Madeleine, le long de la Verzée, entre le Petit et le Grand Moulin. Le présidial d'Angers demande alors la visite et le diagnostic des terrains par un architecte expert. Un rapport très long et détaillé est rédigé et un plan levé. Malheureusement, seul le premier est conservé et, en l'absence du second, sans cesse évoqué dans le texte, il n'est pas toujours facile de localiser les descriptions. On y apprend toutefois une foule de détails. Qu'il existe bien en ce secteur un " mur de ville ", " élevé au-dessus de son sol de quarante pieds dans la majeure partie ", " de cinq pieds six pouces d'épaisseur ", soit haut de $13 \mathrm{~m}$ et épais de 1,50 m. Qu'à son pied se développe le fossé, parfois occupé par des jardins. Qu'ensuite s'élèvent de fortes buttes perturbées, séparées par des passages ou des prélèvements pour la corvée des grands chemins. Nous proposons d'y voir un talus de revers ancien, sans doute médiéval, réalisé avec les terres et roches du creusement du fossé, ce que d'autres actes nomment clairement le "rejet du fossé ". D'ailleurs, sur le plan de 1833, ce secteur est toujours en jardins et en incultes (F2, 537, 563, 564, 565, 595). En un certain endroit plus rocheux, la description est encore plus précise : " Le côté oriental de ces buttes est un roc vif à pic droit faisant la contrescarpe de l'ancien fossé de ville occupé par le jardin de la veuve Lescouvette. " Mieux, le rapporteur décrit " un vestige d'une ancienne tour [...] au côté de l'embouchure de cette ruette " et "de l'autre côté du chemin [...] un autre vestige d'une tour ", ce qui le " fait croire qu'il y avait autrefois en cet endroit une porte de ville ${ }^{66}$ ". Cette porte jamais mentionnée ailleurs démontre donc défi-

64. Rue du faubourg Ridard située avec précision sur le plan d'alignement de 1888 (mairie de Pouancé).

65. Arch. dép. du Maine-et-Loire, 5 E 40/12. Le 14-3-1779 : l'assemblée des paroissiens de Pouancé renouvelle au prêtre détaché de la paroisse de Saint-Aubin pour desservir l'église de la Madeleine, sa rétribution, son logement et ses jardins.

66. Arch. dép. du Maine-et-Loire, 1 B 1000 (12-10-1784), procès-verbal de visite de terrain des Prés marais à Pouancé, à la demande du présidial d'Angers, pour contentieux entre le sieur Dupré et la veuve Blanchet, p. $13 \mathrm{r}^{\circ}$ et $\mathrm{v}^{\circ}$ en particulier. 
nitivement que ce bourg prieural de la Madeleine était clos à la manière d'une ville de la fin du Moyen Âge. Peut-on la localiser exactement? Malgré l'absence regrettable du plan coté, nous pensons qu'elle se trouvait en bas de la rue du faubourg Ridard car dans la description du procès verbal, elle vient juste avant le ruisseau de Bretault, et sur le terrain les deux sont très proches. Qu'en reste-t-il sur le terrain? Peu de choses apparentes, et pourtant quelques détails révélateurs. Du fossé et des buttes, plus rien car ils ont été comblés et arasés, laissant place depuis longtemps au boulevard d'Ancenis et à des jardins, selon un processus très fréquent, surtout au XIX ${ }^{\mathrm{e}}$ siècle. Mais en plusieurs endroits, comme il a été dit plus haut, des fragments du mur de ville et d'abrupt rocheux bien visibles depuis le boulevard d'Ancenis. Et puis, dans deux rues pentues qui descendent depuis la Madeleine vers l'ouest, sur l'axe de l'ancien mur, un léger bombement et parfois le substrat schisteux encore apparent. Enfin, au n ${ }^{\circ} 4$ de l'actuelle rue du chemin de Ronde (ancienne rue du faubourg Ridard), une intéressante maison, construite contre l'escarpement, et sans doute contre ce qui était le mur du bourg de la Madeleine. Elle possède deux caves à des niveaux décalés, la plus basse à peu près en bas de l'escarpement; on y voit le schiste en place. Les deux niveaux supérieurs sont eux aussi appuyés à la paroi et même pour partie creusés dans la roche; ils conservent une façade sur rue avec portes et fenêtres à linteau en accolade, en schiste bleu de Juigné, attribuables au $\mathrm{XVI}^{\mathrm{e}}$ siècle On voit aussi une entrée de cave pour partie creusée dans le roc, et qui donne sur la rue. Ces observations impliquent que cette rue du Chemin de Ronde existait lors de la construction de la maison. C'est près d'elle (vers F2, 534 et 442 ?) que devait se trouver cette porte sud-ouest du faubourg Ridard mentionnée dans les textes, une porte non datable avec précision, mais probablement de la fin du Moyen Âge.

Enfin, le décryptage d'un acte d'afféagement de 1738, permet d'affirmer qu'au milieu du front ouest du bourg prieural se trouvait une autre sortie. C'était celle de " la rue et chemin qui descend du placître de la Magdelaine [...] et se rend au dit chemin qui conduit au Petit moulin ", où était " la maison où demeure Jean Rapin, garde forêt de mondit Seigneur de Villeroy, sise au-dessus et proche le pont de cette ville, appelée la maison du corps de garde ${ }^{67}$ ". Cette mention unique atteste de l'existence d'un pont sur la Verzée, surmonté par une maison dont le nom évoque le contrôle du trafic. On ne peut y voir autre chose qu'une porte ancienne par où sortait originellement l'antique chemin vers la Bretagne. Issue sans doute plus ou moins délaissée en 1738 et capturée au profit du chemin du petit Moulin, vers La Prévière et Ancenis.

\section{Laf acee stdu bo urg}

Dans sa remontée vers le nord, l'éventuel fossé de la Madeleine n'est ni visible sur le terrain, ni présent dans les textes. De forts indices amènent

67. Arch. dép. du Maine-et-Loire, 5 E 40/34. 
cependant à affirmer qu'il existait bien, reliant la porte angevine à l'étang de Bretault, suivant un tracé nord-sud de $90 \mathrm{~m}$ de longueur, à l'emplacement de l'actuelle rue Clémenceau. Sur le plan du XviII ${ }^{\mathrm{e}}$ de Godivier, est en effet figurée une longue et unique parcelle allant de la porte angevine jusqu'au fossé sud de La Madeleine. Si c'est bien un fossé, il était peut-être déjà comblé, mais ses limites marquaient encore suffisamment le parcellaire pour que le géomètre choisisse de le figurer; alors que ce n'est pas le cas des limites mineures, celles de jardins, pourtant fréquemment cités dans les textes du XVIII ${ }^{\mathrm{e}}$ siècle. Il est encore visible sur le plan cadastral de 1833, exactement avec les mêmes limites nord-sud (F2, parcelle 404), mais déjà en cours de colonisation par le bâti au nord (F2, parcelle 403), le long de la grande rue. La largeur approche $15 \mathrm{~m}$ et l'ensemble se raccorde bien aux autres fossés : au nord, à celui de la ville, juste à l'ouest de la porte du bourg castral, dite angevine, tout en laissant celle-ci ouvrir sur l'extérieur en direction de Segré, et au sud au fossé sud de la Madeleine décrit plus haut. Et puis, c'est exactement sur ce tracé que l'enquête et sentence de 1760 déjà citée, place la limite est du fief du prieuré. On observe aussi que cette emprise est le plus souvent légèrement inférieure à $15 \mathrm{~m}$, alors que tous les autres fossés connus sur plan ou sur le terrain dépassent un peu cette largeur. Ce peut être l'indice qu'ils appartiennent à une phase antérieure aux autres. Quand se fit son comblement? Nous pensons que ce fut aussi au $\mathrm{XV}^{\mathrm{e}}$ siècle, en même temps que le creusement du nouveau fossé à l'est de la ville, afin d'unifier le grand espace protégé au sud et à l'est du château et de son bourg castral tel qu'on le voit sur le plan de 1781. Il y a fort à penser que c'est dans cette même dynamique que les fossés sud et ouest de la Madeleine ont été recreusés et dotés d'un talus, ainsi qu'ils apparaissent dans les actes du XVIII ${ }^{\mathrm{e}}$ siècle.

On peut donc conclure que le bourg prieural de la Madeleine, fut réellement protégé et même défendu, d'abord par sa position élevée, mais aussi par l'aménagement de fossés, de talus et de murs. On est aussi certain qu'il était doté d'au moins une porte à deux tours au bourg Ridard, et peut-être d'une ou deux autres, si l'on se réfère au plan de 1781. Cette clôture est quasi certaine au moins au $\mathrm{XV}^{\mathrm{e}}$ siècle, moins évidente, mais possible aux $\mathrm{XI}^{\mathrm{e}}$ et $\mathrm{XII}^{\mathrm{e}}$ siècles. Ce fait rarement signalé se rencontre cependant pour un certain nombre d'autres bourgs monastiques ${ }^{68}$ : à Rillé en Fougères et à Sainte-Croix de Vitré dans les textes, dès les $\mathrm{XI}^{\mathrm{e}}$ et XII ${ }^{\mathrm{e}}$ siècle, et on l'observe aussi sur les cadastres du XIX ${ }^{\mathrm{e}}$ siècle à Marcillé-Robert (35), à La Gravelle et à Ballots (53).

68. Meuret, Jean-Claude, "Origines et débuts des villes de la marche bretonne... ", p. 56, dans ChÉDEville, André et Pichot Daniel (dir.), Des villes à l'ombre des châteaux. Naissance et essor des agglomérations castrales en France au Moyen Âge, PUR, 2010, p. 43-64. 


\section{La rivière Verzée et son franchissement}

Un quatrième point a pu être étudié et détaillé dans son évolution longue : la place de la rivière Verzée et son franchissement par la voirie menant en Bretagne (fig. 10-11-12-13).

\section{Figure 10 - Plan des issues de Pouancé fin $\mathrm{XI}^{e}$ siècle (J.-C. Meuret)}

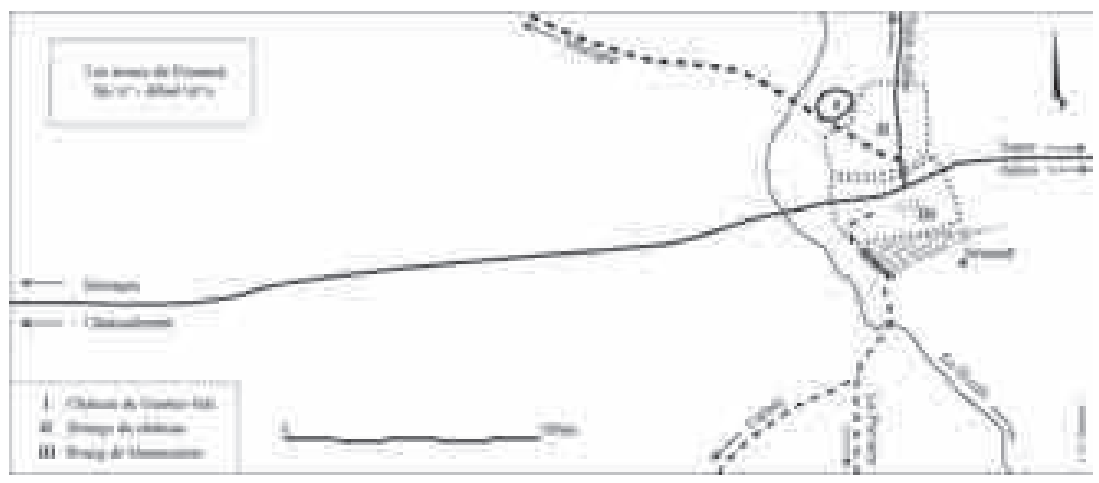

Figure 11 - Plan des issues de Pouancé XIII siècle (J.-C. Meuret)

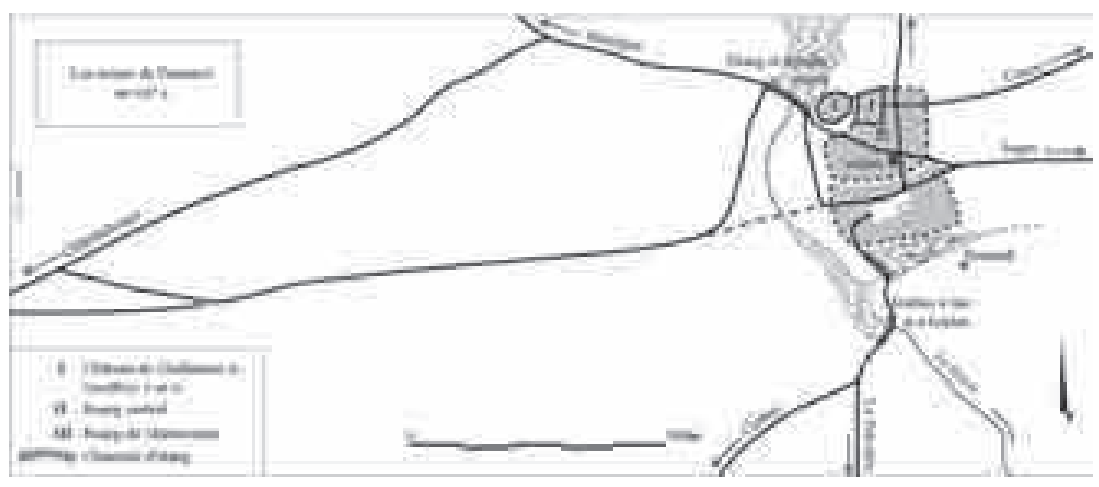

La ville de Pouancé s'est essentiellement développée sur la rive gauche de la Verzée, sur le rebord d'un plateau plus élevé et rocheux de ce côté est. Un peu comme si, à l'origine du château - soit au milieu du $\mathrm{XI}^{\mathrm{e}}$ siècle selon les textes conservés - cette modeste rivière tenait lieu de front et limite linéaire bien visible, entre les terres du comte d'Anjou, et celles de la Bretagne, détenues par Brient, premier seigneur de Châteaubriant. Il en résulte que tout au long des dix siècles d'évolution de la ville, les issues du château et de la ville sur sa face ouest n'ont cessé de varier au gré des aménagements réalisés. 
Figure 12 - Plan des issues de Pouancé $X V^{e}$ siècle (J.-C. Meuret)

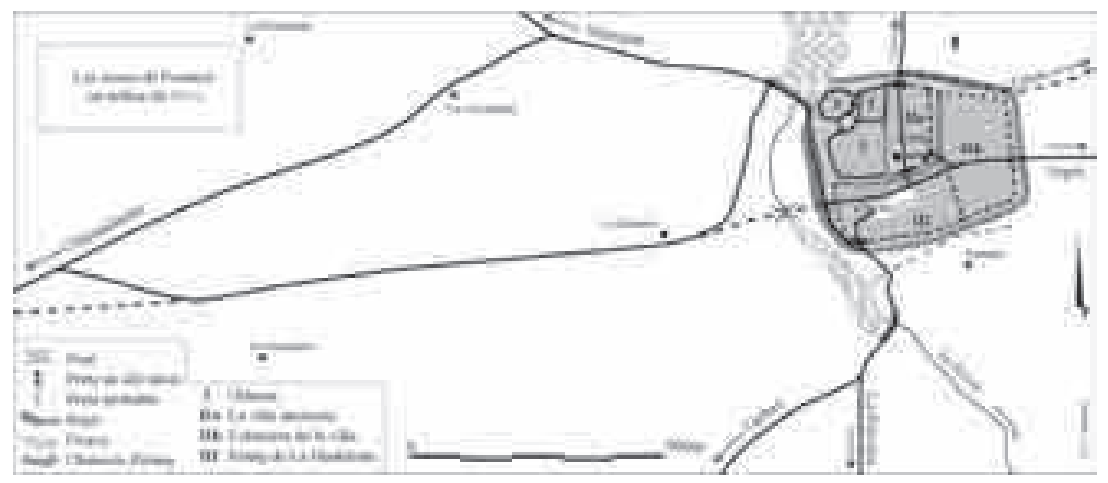

Figure 13 - Plan des issues de Pouancé XVIII -XIX ${ }^{e}$ siècle (J.-C. Meuret)

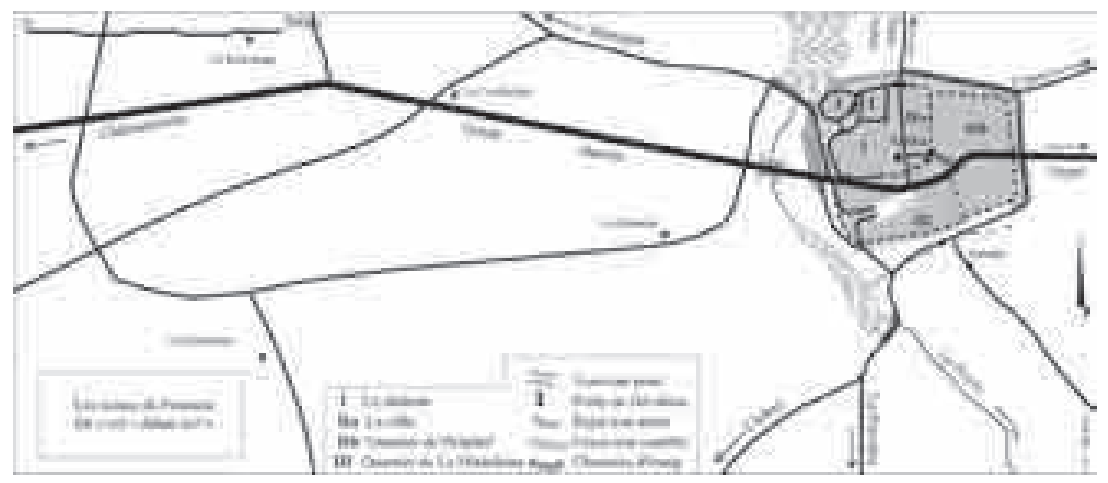

Le premier franchissement fut celui de la voie ancienne Angers-Carhaix. Celle-ci arrivait de l'est depuis Vergonnes et passait au cœur de la future ville. $\mathrm{Au} \mathrm{XI}{ }^{\mathrm{e}}$ siècle, le château fut, semble-t-il, implanté à quelques mètres au nord du tracé, tandis que les moines installaient leur bourg sur son passage même. Ainsi le trafic entre Anjou et Bretagne faisait-il l'objet d'un double contrôle. Le chemin passait au bord de l'église; il s'élargissait ensuite pour former la place plus tard nommée placître, où devaient se dérouler les transactions; il descendait ensuite en ligne droite et plein ouest pour franchir la rivière et remonter le coteau de la rive droite en passant par la Saunerie. À partir de ce lieu, il continuait en droite ligne vers l'ouest et la Bretagne. Cependant, sur les plans des XVIII ${ }^{\mathrm{e}}$ et $\mathrm{XIX}^{\mathrm{e}}$ siècle, si cette rue descend bien la pente du bourg de la Madeleine en droite ligne, elle s'incurve brutalement à droite au niveau des anciens murs du bourg prieural et se dirige vers la chaussée du Grand Moulin. Si on regarde sa suite à l'ouest, nommée le vieux chemin de Châteaubriant à Pouancé sur le cadastre de 1833, on observe 
aussi un brutal changement de direction : alors que depuis Soudan, puis le nord de Carbay, il fossilise en droite ligne la voie antique, on le voit s'incurver brutalement à partir de la Saunerie, pour se raccorder lui aussi à la chaussée du Grand Étang. À l'évidence, il s'agit là d'un phénomène de capture, la voie primitivement rectiligne ayant été déviée pour passer sur la chaussée du grand étang. Il a été dit plus haut que cette dernière fut construite au début du XIII ${ }^{\mathrm{e}}$ siècle à l'époque de Guillaume III. Pour autant, la capture que l'on observe peut ne pas s'être produite immédiatement après la création de la chaussée. C'est ce qu'amène à penser l'examen conjoint des données cartographiques, textuelles et de terrain. Ainsi, dans l'acte de 1220 , il est fait mention de trois chemins orientés vers l'ouest et donnant sans doute lieu à péage, ceux de Martigné, de Châteaubriant et de Carbay ${ }^{69}$. Le premier devait sortir au nord-ouest de la ville par la porte condamnée étudiée plus haut : elle s'ouvrait sur le fossé du château, à proximité immédiate de la chaussée de l'étang neuf, vers l'ouest/nord-ouest, en direction de Martigné. Elle reliait Pouancé et Martigné, les deux entités foncières qui composaient la châtellenie jusqu'à la mort de Gautier Hai, au début du XII ${ }^{\mathrm{e}}$ siècle Le second sortait au sud-est du bourg de la Madeleine, par la porte du bourg Ridard, révélée, on l'a vu, par deux textes du XVIII ${ }^{\mathrm{e}}$ siècle Il bénéficia lui aussi très tôt, d'une chaussée d'étang, celle du Petit Moulin. Ce dernier est bien identifié comme moulin à tan sous l'Ancien régime, sa petite retenue d'eau apparaît sur la carte de Cassini, et son origine remonte au XIII siècle puisque sa construction était annoncée dans la charte de 1220 (molendinum ad tamnum pilandum). Ce chemin menait non seulement vers Carbay, mais bifurquait aussi vers le sud en direction de La Prévière et au-delà vers Ancenis. Enfin, il semble que le troisième, sortait au milieu de la face ouest du bourg de la Madeleine. C'était l'antique chemin d'Anjou en Bretagne. Il a été dit que dans un acte de 1738, c'est lui qui descendait du placître de la Madeleine, franchissait la Verzée sur le pont de la ville, pour remonter vers la Saunerie, et se diriger vers Châteaubriant. Signes d'une fréquentation ancienne, des boulets de pierre furent découverts dans les années 1980 non loin de la Saunerie, près des Hesnières et près de la Crochetière, et alors mis en rapport avec le siège de Pouancé par les Bretons en 1432. Sa sortie de ville semble avoir été contrôlée par une porte dont " la maison du corps de garde " de 1738 aurait gardé le souvenir. Quant au " pont de la ville " cité dans le même acte, il ne doit pas être confondu avec celui de l'actuelle route de Châteaubriant qui l'un et l'autre ne furent construits que plus tard, en 1767 et $1768^{70}$. Ce pont ne semble plus exister à la fin du XVIII ${ }^{\mathrm{e}}$ siècle, car

69. Arch. dép. du Maine-et-Loire, 43 H 1/6 (vers 1220) : "vicariam quam ego habeo in tribus chiminis quod unus ducit ad Carbae, alius ad Castrum Brientii, tertius ad Martiniacum ".

70. NEAU, André, Sur les chemins de l'Histoire..., p. 201-202. Ils le furent à l'occasion de l'ouverture d'une liaison Laval Nantes par Craon, Pouancé et Châteaubriant réalisée par le moyen de la corvée royale. De nombreux actes d'afféagement ou de vente font mention des travaux de la corvée et des terrassements réalisés dans les abrupts du pied du bourg de la Madeleine pour tirer de la pierre. C'est à cette occasion que fut comblé le fossé sudouest de la ville et nivelé l'angle nord-ouest du bourg de la Madeleine afin d'y installer 
un afféagement de 1773 fait mention d'" une portion de douve au creux du fossé situé au-dessous du Grand Jardin du Château [...] occident le grand chemin tant de Châteaubriant que de Martigné ou du Grand Moulin ${ }^{71}$ ". Il n'existerait donc plus alors qu'un seul chemin par le Grand Moulin pour aller vers Martigné et Châteaubriant : la capture de l'antique chemin par la chaussée de l'étang semblerait alors achevée. Mais en réalité, à la date de 1773, ce constat est déjà dépassé, puisque depuis 1768 la toute nouvelle route royale nommée grand chemin et son pont ont coupé cette capture et mènent à nouveau en droite ligne vers Châteaubriant. Ce que confirme un acte de 1778 où il est précisé qu'un terrain situé dans ce secteur a été " rompu par le grand chemin " et qu'il est limité "d'orient par l'ancien chemin de Pouancé à Martigné, et au nord par le dit nouveau grand chemin ${ }^{72}$ ".

\section{Le“ terraindu pa tronage »}

Le dernier point, le plus important selon nous, a trait à ce grand espace non bâti de la ville nommé " quartier du château " sur le cadastre de 1833 et aujourd'hui connu sous la dénomination de "terrain du patronage ». Ce vaste espace de presque un hectare intrigue à plus d'un titre. À la vue de tous les plans, du XVIII ${ }^{\mathrm{e}}$ siècle jusqu'à aujourd'hui, on est d'abord frappé par le fait que, bien que contigu à la ville et clos de murailles, il n'est absolument pas construit. D'autre part, lorsqu'il est cité dans les textes, soit à partir du XVIII ${ }^{\mathrm{e}}$ siècle, paradoxalement, il est toujours inclus dans le château, mais désigné comme pré ou jardin. Ainsi, en 1720, l'acte de vente d'une maison de la place des halles comprend " un petit jardin au derrière de laditte maison clos par les murs du jardin du Chasteau "73 ". En 1773, il est localisé avec précision et désigné comme " le grand jardin du château ${ }^{74}$ ». En 1790, c'est sans doute lui que le duc de Villeroy compte comme jardin dans les 3 arpents de sa forteresse en ruine ${ }^{75}$. Dans les biens confisqués en l'an 3 ,

l'actuelle grande rue de la Libération. Ces grands travaux nous empêchent de comprendre aujourd'hui, aussi bien sur le plan de 1833 que sur le terrain, comment, dans ce secteur, s'articulaient les fossés et les murs de la ville et de la Madeleine.

71. Arch. dép. du Maine-et-Loire, 5 E 40/43. Afféagement du 2 sept. 1773 par le seigneur de Pouancé.

72. Arch. dép. du Maine-et-Loire, 5 E 40/66. Partage des biens de la succession de Charles Pouriat. En marge de cette citation, il est précisé que ce terrain est "sittué au bas du faubourg de la Magdelaine de cette ville".

73. Arch. dép. du Maine-et-Loire, 5 E 20/175 (6 avril 1720), p. 2.

74. Arch. dép. du Maine-et-Loire, 5 E 40/43.

75. Arch. dép. du Maine-et-Loire, C 337. Requête du duc de Villeroy à Messieurs les administrateurs de la province d'Anjou et commissions intermédiaires : «M. de Neuville, duc de Villeroy, seigneur baron de Pouancé a toujours affermé par baux authentiques ses domaines, ses forges à fer, ses droits féodaux et généralement tout ce qui dépend de sa terre et le compose. Il en excepte cependant un vieux château et forteresse en totale ruine environ 3 arpents de terre, en jardin, pré, verger et terre labourable qui sont laissés à son garde... " 3 arpents (1 ha 1/2), c'est à peu près le total du château, de sa basse-cour, du terrain du patronage, non compris les fossés (voir le tableau suivant). 
on le désigne encore comme un pré de 3 hommées attenant au château ${ }^{76}$. Un jardin, ou un pré, fortifié par des tours et de hautes murailles, voilà qui est peu commun, et laisse supposer un changement de destination. Sur le plan de 1833, il consiste en une grande parcelle (F2, 187) nommée « quartier du château " sur laquelle se greffe une plus petite (F2, 157). Lorsqu'on s'y rend aujourd'hui, on constate qu'il est toujours vide, et on est frappé par son aspect et sa situation : un espace plan et presque parfaitement plat, contenu au sud et à l'ouest par des murailles encore hautes de 6 à $10 \mathrm{~m}$, dominant les fossés ouest et la vallée de la Verzée de $15 \mathrm{~m}$. À sa limite est, là où se trouve le parking, cet espace se trouve à environ 1,50 m sous le niveau de la ville et séparé de celle-ci par un petit mur-terrasse hétérogène; de ce côté originellement plus élevé, il se trouve donc en déblai. Au nord, il est délimité et contenu par un haut mur qui domine d'environ $10 \mathrm{~m}$ la partie sud du fossé du château.

Or, il communique, ou plutôt communiquait, avec ce fossé du château par une porte en arc brisé (fig. 14) qu'on attribue de manière un peu floue $\mathrm{au} \mathrm{Xv}{ }^{\mathrm{e}}$ siècle. Cette porte est obturée du côté du fossé. On ne voit son ouverture que du côté interne, et seulement grâce à un creusement presque vertical, visiblement une reconnaissance " archéologique " récente, mais qu'on aimerait pouvoir dater avec plus de précision. L'ouverture mesure 2,30 m de largeur et sa hauteur dégagée sous l'arc est d'environ 2,35 m. Son niveau de circulation est donc toujours enfoui, au moins $1 \mathrm{~m}$ plus bas. Actuellement, le sommet de son arc brisé se trouve à $0,70 \mathrm{~m}$ sous le niveau général du terrain du patronage. La porte est donc totalement enterrée sous au moins $4 \mathrm{~m}$ de remblais et par là même rendue totalement non fonctionnelle; si le comblement et nivellement de la terrasse au niveau et contre cette porte est bien ancien - il faudrait pouvoir vérifier dans les sources qu'il n'y a pas eu d'apports en cet endroit au XVIII ${ }^{\mathrm{e}}$ au et XX $\mathrm{X}^{\mathrm{e}}$ siècle cela implique que la plate-forme a été créée grâce à un très fort remblai et cela postérieurement à la construction de la porte. D'autre part, l'ouverture de celle-ci est obturée verticalement à 1,40 m dans l'épaisseur du massif et par un mur d'un appareil un peu différent de celui de l'arc. Des deux côtés de la courtine de ville, le massif rectangulaire dans lequel est incluse cette porte est en saillie, mais s'il est bien ouvert côté interne, il est totalement fermé et plan côté fossé du château. Les conclusions de ces observations et relevés sont nets : d'une part, cette porte de ville a été obturée par un mur de 2,60 m d'épaisseur côté fossé du château, au-dessus de la poterne sud de celui-ci; d'autre part, elle a été remblayée et même totalement enterrée côté interne par un fort remblai.

76. Arch. dép. du Maine-et-Loire, 73 Q 2. Biens confisqués, an 3 : « Le ci-devant château de Pouancé et la prée y attenant contenant trois hommées, le jardin de maître et la maison occupée par Guillaume... " En Anjou, l'hommée, quand elle est la surface bêchée par un homme en une journée équivaut à peine deux ares, mais quand elle concerne un pré et donc la surface fauchée par un homme dans le même temps, elle varie de 1200 à $4400 \mathrm{~m}^{2}$, pour s'établir à un tiers d'hectare à Saumur. Cette dernière valeur convient bien au quartier du château qui mesure environ $9600 \mathrm{~m}^{2}$. 
Pouancé ou la constitution d'une ville castrale en Bretagne et Anjou

Figure 14 - Élévation et plan de la porte obturée du terrain du patronage (J.-C. Meuret)

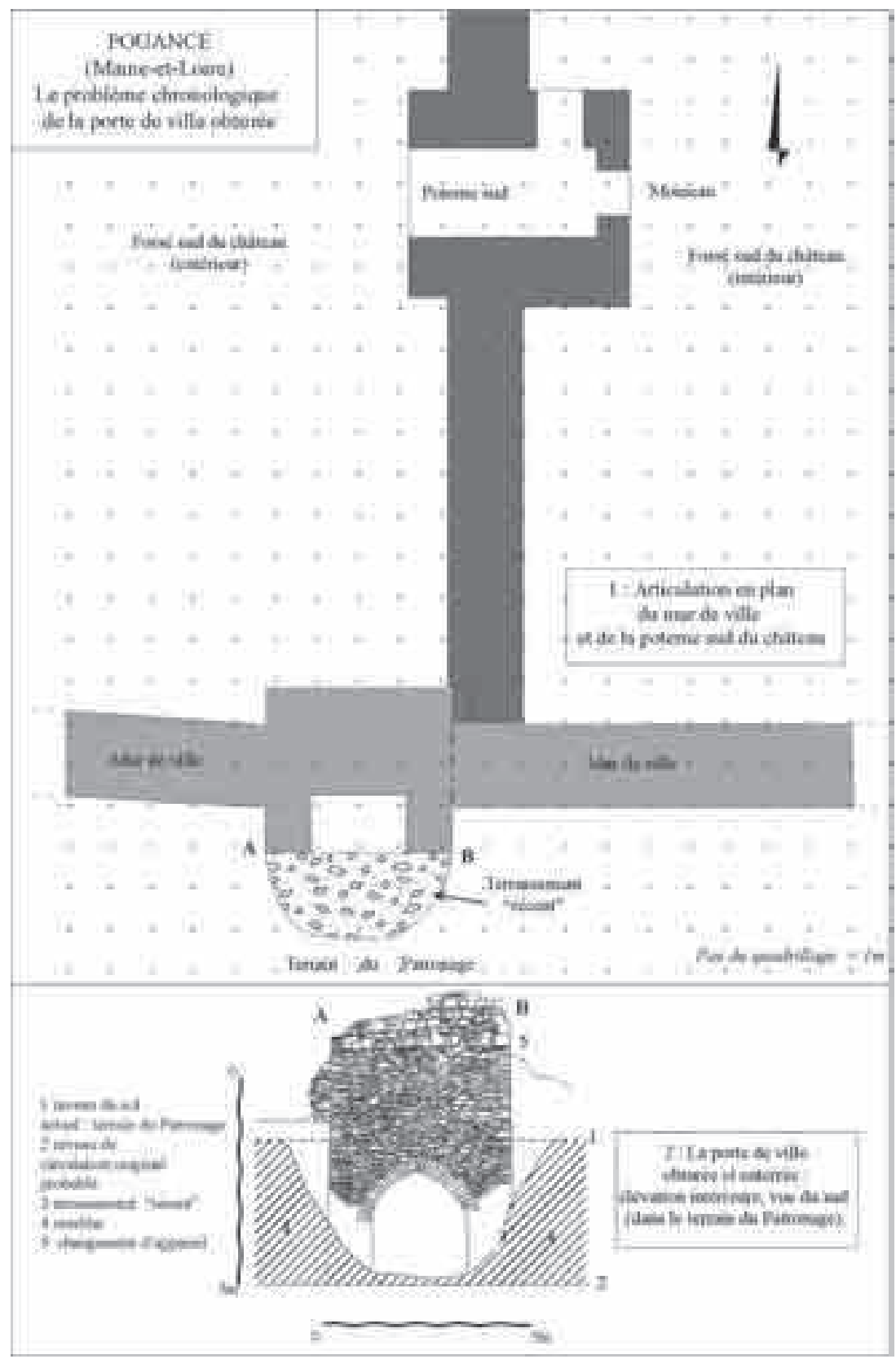


L'existence de ce comblement et de l'instabilité du mur qui le contient est apparue à plusieurs reprises. En mars 1978, puis janvier 1982, la tour dite " carrée " de l'angle nord-ouest s'est fissurée, puis écroulée en même temps qu'un pan de courtine. À cette occasion, on a pu observer que celle-ci était en réalité un massif rectangulaire plein, vraisemblablement destiné à raidir la courtine et contrebuter l'énorme poussée du remblai. Il en était sans doute de même pour l'autre massif quadrangulaire visible au milieu de la courtine ouest, sur le plan Godivier. La présence de ces massifs pleins et dépourvus d'ouvertures de tir, au moins sur les photos dont on dispose, étonne un peu : sur cette face ouest de la ville, orientée vers la Bretagne, on se serait plutôt attendu à des tours d'artillerie. Mais, deux indices amènent à penser que toute cette courtine ouest n'est plus dans son état originel, et que la plus ancienne peut se trouver en arrière, noyée dans le remblai : d'une part, dans sa partie la plus ancienne, au contact de la porte obturée, son appareil est constitué non de petites plaquettes de schiste comme presque partout ailleurs dans les murs du Xve siècle, mais de blocs de grès d'un module plus important; et surtout, lors d'un effondrement de la partie sud, proche de la tour à bec, en 1963, Louis Bessière a pu observer que le mur écroulé était construit en avant du mur de fortification initial. Le départ de ce dernier se voyait en arrière, encore attaché à la tour ${ }^{77}$.

Plus récemment, en février 1995, sur ce côté ouest, un autre pan de la courtine s'est effondré à l'emplacement de la salle de boule de Fort, sur une longueur d'environ 20 m. Une partie vient d'être reconstruite en 2009-2010. En cet endroit où la pente est très forte, la plate-forme domine l'actuel fond de la douve de $15 \mathrm{~m}$, et au vu de la partie de courtine effondrée et de ses éboulis, on peut estimer l'épaisseur du remblai autour de $8 \mathrm{~m}$. Il est certain que ce sont des milliers de $\mathrm{m}^{3}$ qui ont été apportés là pour constituer la plate-forme. Peut-être proviennent-ils, au moins pour partie, des creusements et recreusements des grands fossés de la ville que nous pensons avoir été réalisés au $\mathrm{XV}^{\mathrm{e}}$ siècle.

Enfin, au sud de cet espace se voient encore deux tours. De l'extérieur, on ne peut en rien les observer en raison de la présence de bâtisses appuyées contre elles. La plus occidentale est sans intérêt car arasée et aménagée en 1948, à l'occasion d'une mission, pour porter un portique et un socle de béton destinés à encadrer et soutenir une croix. La seconde, située au sud-est de la plate-forme présente plus d'intérêt. C'est une tour «à bec ", ouverte à la gorge, et dotée d'une chambre de tir pour pièce d'artillerie; l'orifice de tir est toujours visible, ainsi que les logements latéraux pour le calage de l'arme. De plus, cette chambre et son orifice de tir se trouvent à des niveaux parfaitement compatibles et fonctionnels par rapport à celui de l'ensemble de la plate-forme. Or dans un acte du milieu du XVII ${ }^{\mathrm{e}}$ siècle, il

77. L'OEIL DE B(Euf (= Louis BessiÈre), " Pouancé, le mystère des remparts ", Le Courrier de l'Ouest, déc. 1963. 
est fait mention d'une tour de la Terrasse ${ }^{78}$ située dans ce secteur; une telle dénomination évoque sans aucun doute un lien direct avec l'artillerie ${ }^{79}$.

L'ensemble constitue donc un espace original et problématique : on y observe un très fort remblai, accumulé sur un terrain originellement en pente, afin d'en faire une vaste esplanade surélevée. Le niveau de celle-ci est le même que celui où a fonctionné une tour d'artillerie de sorte que le remblai semble dater du $\mathrm{xv}^{\mathrm{e}}$ siècle D'autre part, la tour-porte obturée, à l'appareil et aux matériaux archaïques, enterrée sous le remblai, ne peut qu'être antérieure à celui-ci et au plein $\mathrm{xv}^{\mathrm{e}}$ siècle. Enfin l'absence totale de tout reste bâti ancien, autant dans les textes qu'in situ, mise en parallèle avec l'existence du fort remblai, incite à lui attribuer une fonction particulière et non résidentielle.

Pour tout dire, on ne peut s'empêcher d'envisager l'hypothèse d'un aménagement de ce lieu au cours du $\mathrm{XV}^{\mathrm{e}}$ siècle, lorsque la place fut choisie comme base avancée pour l'armée et l'artillerie royales. Il faut ici rappeler que Jean II d'Alençon, seigneur de nombreuses terres, dont Pouancé, participa à de nombreux " complots " contre la monarchie française dans la première moitié du Xv siècle, en pleine Guerre de Cent ans. Ses biens furent confisqués, jusqu'à ce que Louis XI rétablisse son fils René dans son droit d'héritage, en 1475-1477. Cependant le roi excepta de la restitution les places fortes « la ville et chastel de Damfront avecques ses appartenances, le chastel, baronnie, terre et seigneurie de Pouencé, avec ses appartenances, le chastel et place de Sainte Susanne avec la valleur de 300 livres de rente prinses sur le revenu de la dicte seigneurie et tant sur la ville que dehors, lesquelles villes, places, chasteaux et forteresses dessus dictes, pour aucunes causes à ce nous mouvans, mesmement qu'elles sont en pays de frontières et clefz des pays voisins et qu'elles sont de fortes gardes, nous avons retenus et retenons à nous et à noz successeurs rois de France ${ }^{80}$ ". Ce texte révèle l'importance majeure que revêtait Pouancé dans la stratégie royale et il rend

78. Arch. dép. du Maine-et-Loire, 4 U 25/1 (copie de 1806) : "La douve du fossé de cette ville et côté a été concédée à Henri Lescouvette pour y faire faire un jardin planté des arbres, et faire pâturer des bestiaux depuis la porte angevine dite porte de l'horloge jusqu'à la tour de la terrasse pour d'icelle douve jouir lui et ses hoirs et ayant cause à l'avenir à la charge de payer chacun an une rente en argent et sans autre réserve que celle de ne rien faire qui puisse diminuer la fortification dudit fossé, qu'en conséquence de cette concession faite en mil six cent quarante trois et mil six cent quarante huit ledit Lescouvette ses hoirs et ayant cause ont fait faire des jardins dans la ditte douve et $\mathrm{y}$ ont fait planter des arbres tant en haute tige qu'en espalier partout où ils l'ont jugé convenable et notamment sur le talus ou côté qui existe au pied du mur qu'a fait démolir en partie le sieur Foullieul, lequel mur fermait l'embrasure de l'ancienne porte de la Madeleine, avant les concessions et était alors le lieu des prisons de cette ville. "

79. Salamagne, Alain, Construire au Moyen Âge. Les chantiers de fortification de Douai, Presses Universitaires du Septentrion, 2001, p. 81.

80. Chartes servant de pièces justificatives à la géographie du Perche et formant la cartulaire de cette province, publiées par RomAnET, Vicomte de, Mortagne, 1890-1902, acte $\mathrm{n}^{\circ} 79$ (entre 26 mars 1475 et le 16 avril 1477, n.s.). Lettres patentes du roi rétablissant René d'Alençon dans le droit d'hériter de son père, excepté Domfront, Pouencé et Sainte-Suzanne. 
très vraisemblable la réalisation d'importants travaux de mise en défense dans les décennies qui ont précédé 1488. Les venues et installations de Louis $\mathrm{XI}^{81}$, puis Louis II de la Trémoille à Pouancé ${ }^{22}$, se placent dans ce siècle où les défenses castrales et urbaines subissent de profondes mutations pour être adaptées à l'artillerie. À Pouancé, le château connaît de nombreuses adaptations successives, pas toujours bien datées, mais toutes destinées à en faire un réduit ultime, sinon imprenable : fermeture du fossé au sud et à l'est par des poternes, puis condamnation de ces dernières lors de la création des moineaux, construction de la tour heptagonale, de la caponnière, du bastion... Tout incite à penser que c'est dans cette période sous Charles VII ou Louis XI, que fut créée la grande plate-forme dont on parle ici. Elle aurait consisté à fortement remblayer sur les $2 / 3$ un espace en pente vers l'ouest, pris sur l'agglomération castrale, sur un de ces bourgs déjà signalés dans les chartes de 1094, dont seule subsisterait la porte scellée et obturée. Ainsi aurait été créé un espace à la fois haut, plan, vaste, ce que n'offrait pas le château, défendu par au moins une tour d'artillerie, et orienté à l'ouest, face à la Bretagne. En résumé, un lieu parfaitement adapté pour l'accueil d'une partie de l'armée royale et en même temps de sa précieuse artillerie. Notons que cette hypothèse, fortement étayée par de nombreux arguments, implique un profond changement dans l'évolution et l'organisation urbaine : l'ouverture directe de la ville castrale par cette porte sur le chemin vers Martigné et Rennes condamnée et reportée ailleurs, mais où? Toute une partie de la ville originelle scellée sous des mètres de remblais et donc une partie de la population déplacée, peut-être vers la partie nouvellement enclose à l'est; une chapelle Saint-Pierre dorénavant ouverte à l'ouest sur un espace totalement inhabité, ce qui peut avoir amené sa désaffection. Il n'est pas possible d'assigner une décennie précise pour la réalisation de cette plate-forme : la chronologie relative des murs permet seulement de dire qu'elle est au moins contemporaine de la poterne sud du château, sinon antérieure. Dans ces conditions, comment ne pas rêver à des fouilles ou au moins à des investigations électro-magnétiques sous cette plate-forme !

Nous terminons cette étude de Pouancé par deux tableaux comparatifs. Le premier présente les superficies occupées par les trois entités connues à la fin du Xi ${ }^{e}$ siècle à partir de la charte de 1094, des plans et du terrain : le château, les bourgs castraux et le bourg prieural. Si la première et la dernière sont assez sûrement délimités, il n'en est pas de même pour le secteur des bourgs, mal situés et sans doute non jointifs. La superficie totale de 5,20 ha incluait des espaces non urbanisés, aussi bien dans le secteur des bourgs castraux que dans le bourg prieural : on pense aux vignes citées dans la charte. Il en résulte une assez grande marge d'incertitude. Des fos-

81. Pour la présence de Louis XI à Pouancé : NEAU, André, En pays pouancéen..., p. 63-66. 82. Correspondance de Charles VIII et de ses conseillers avec Louis ii de la Trémoille pendant la guerre de Bretagne. 1488, publiée d'après les originaux par LA TRÉMOILLE, Louis de, Paris, 1875, rééd. Mégariotis Reprints, Genève, 1978. Parmi les places arrière de l'armée française, on relève 18 mentions d'Angers, 10 de Pouancé, 10 de Craon, 6 de ChâteauGontier, 1 de Segré. 
sés existaient à cette époque, on en a la certitude, mais on ne connaît pas leurs dimensions, car ils ont été très recreusés aux siècles suivants. Pour cette raison, il n'a pas été tenté de chiffrer leur emprise.

\section{Figure 15a - Tableau des emprises des différentes entités urbaines fin $\mathrm{XI}^{e}$ siècle (J.-C. Meuret)}

\begin{tabular}{|l|c|c|}
\hline & Superficie enclose & \% des sup. encloses \\
\hline Château & $2150 \mathrm{~m}^{2}$ & $4 \%$ \\
\hline Basse-cour du château & $2150 \mathrm{~m}^{2}$ & $4 \%$ \\
\hline Bourgs castraux & $25250 \mathrm{~m}^{2}$ & $48,5 \%$ \\
\hline $\begin{array}{l}\text { Bourg monastique } \\
\text { (la Madeleine) }\end{array}$ & $22500 \mathrm{~m}^{2}$ & $43,5 \%$ \\
\hline Total & $52050 \mathrm{~m}^{2}$ & $100 \%$ \\
\hline
\end{tabular}

De ce tableau, il faut avant tout retenir l'importance du bourg de la Madeleine, pendant les premiers siècles, ceux de la genèse de la ville : il couvrait alors $43,5 \%$ des surfaces occupées, alors que les bourgs supposés en couvraient $48,5 \%$. C'est le reflet du poids qu'a eu dès l'origine ce prieuré, aux plans religieux (quatre moines), mais aussi humain, économique et seigneurial.

\section{Figure 15b - Tableau des emprises des différentes entités urbaines au $\mathrm{XV}^{e}$ siècle (J.-C. Meuret)}

\begin{tabular}{|c|c|c|c|c|c|}
\hline Entité spatiale & $\begin{array}{c}\text { Superficie } \\
\text { enclose }\end{array}$ & $\begin{array}{c}\text { \% des sup. } \\
\text { encloses }\end{array}$ & $\begin{array}{c}\text { Superficie } \\
\text { des fossés }\end{array}$ & $\begin{array}{c}\% \text { de la sup. la sup. } \\
\text { des fossés }\end{array}$ & $\begin{array}{c}\text { des fossés } \\
\text { par rapport à } \\
\text { la sup. qu'ils } \\
\text { enclosent }\end{array}$ \\
\hline Château & $2150 \mathrm{~m}^{2}$ & $3,5 \%$ & $3450 \mathrm{~m}^{2}$ & $10 \%$ & $160 \%$ \\
\hline $\begin{array}{c}\text { Basse-cour du } \\
\text { château }\end{array}$ & $2150 \mathrm{~m}^{2}$ & $3,5 \%$ & $750 \mathrm{~m}^{2}$ & $2 \%$ & $35 \%$ \\
\hline Bourg castral (ville) & $16300 \mathrm{~m}^{2}$ & $21 \%$ & $9100 \mathrm{~m}^{2}$ & $25 \%$ & $56 \%$ \\
\hline $\begin{array}{c}\text { Bourg monastique } \\
\text { (la Madeleine) }\end{array}$ & $22500 \mathrm{~m}^{2}$ & $29,5 \%$ & $\begin{array}{c}8200 \mathrm{~m}^{2} \\
\left(+2250 \mathrm{~m}^{2}\right) \mathrm{a}\end{array}$ & $23 \%$ & $36 \%$ \\
\hline $\begin{array}{c}\text { Quartier du châ- } \\
\text { teau (plate-forme) }\end{array}$ & $8950 \mathrm{~m}^{2}$ & $11 \%$ & $4400 \mathrm{~m}^{2}$ & $12 \%$ & $49 \%$ \\
\hline $\begin{array}{c}\text { Quartier de l'hos- } \\
\text { pice }\end{array}$ & $26400 \mathrm{~m}^{2}$ & $31,5 \%$ & $9950 \mathrm{~m}^{2}$ & $28 \%$ & $38 \%$ \\
\hline Total & $78450 \mathrm{~m}^{2}$ & $100 \%$ & $35850 \mathrm{~m}^{2}$ & $100 \%$ & $45 \%$ \\
\hline
\end{tabular}

$\mathrm{a}\left(+2250 \mathrm{~m}^{2}\right)$ : fossé est de la Madeleine, déjà comblé au XVIII ${ }^{\mathrm{e}}$ siècle et sans doute dès le $\mathrm{XV}^{\mathrm{e}}$ siècle (Superficie totale de la ville close : 11,43 hectares, dont $31 \%$ de fossés) 
Le second permet de comparer les différentes entités urbaines au $\mathrm{XV}^{\mathrm{e}}$ siècle avec beaucoup plus de précision. À partir du plan de 1833, les superficies encloses ont pu être mesurées assez exactement. C'est moins le cas pour celles des fossés : si ceux de la ville et du quartier de l'hospice sont bien délimités, il n'en est pas de même pour ceux du château et du bourg de la Madeleine, alors en cours de comblement et de colonisation par le bâti ${ }^{83}$.

Ce tableau présente un zonage bien différent de l'évaluation du $\mathrm{XI}^{\mathrm{e}}$ siècle : Pouancé s'est structurée, urbanisée et militarisée. Les textes font alors régulièrement mention de " la ville ", il en est de même pour les restes bâtis visibles ou connus. La ville proprement dite a perdu le quartier du château, annexé à celui-ci pour une probable fonction de défense; en revanche elle a gagné un quartier, celui de «l'hospice » qui devait alors s'appeler " la Rouërie ». Cela représente au total 52,5\% des surfaces encloses. Quant au bourg monastique, il n'en couvre plus que 29,5\%, seulement les $3 / 10^{\mathrm{e}}$, chiffre qui signe son déclin par rapport aux débuts. Un autre chiffre à retenir est celui de la plate-forme dite " quartier du château " : 11 \% des superficies encloses au XV siècle. Qu'un espace aussi important ne soit pas bâti implique, comme il a été dit, une destination spécifique et importante. Enfin, le tableau met en évidence l'importance des fossés; ceux-ci couvrent plus de 3,5 ha, $45 \%$ des surfaces closes, ou encore $31 \%$ de la superficie totale de la ville. Si on leur attribue une profondeur moyenne de $4 \mathrm{~m}$ cela implique le déplacement d'environ $140000 \mathrm{~m}^{3}$ de terre et de roche. L'essentiel semble l'avoir été au Xve siècle. Même si ce chiffre n'est qu'une approximation, il permet cependant de se figurer l'importance des "rejets " (talus externes) qui doublaient les fossés et l'activité qu'il a fallu déployer pour mettre la ville entière en défense. Aucun texte médiéval n'évoque ces énormes travaux et cela montre bien qu'une telle étude ne peut en aucun cas se limiter à la seule approche par les sources écrites.

Peu lisible au premier regard, l'évolution de la ville de Pouancé apparaît maintenant avec plus de clarté (fig. 16). La ville plonge ses racines dans un passé millénaire : née à peu de distance d'un centre paroissial attesté au haut Moyen Âge, celui de Saint-Aubin, et installée sur un axe majeur estouest d'origine gallo-romaine, au contact de deux cités antiques. Toutefois, l'essentiel de son développement s'est fait à partir et autour d'un château en un long processus séculaire. La création du tissu de l'agglomération peut paraître avoir résulté de décisions seigneuriales précises : ainsi la forte dotation du prieuré de Marmoutier par Gautier Hai ou la création du grand étang et de ses moulins par Guillaume III. Mais outre le fait que nombre d'autres décisions n'ont pas laissé de traces écrites, on doit aussi replacer celles-ci dans des contextes idéologiques ou politiques séculaires diffus, non pensés mais prégnants : parmi eux, on pense à la réforme grégorienne

83. Chiffres arrondis à la centaine de $\mathrm{m}^{2}$ la plus proche. 
Pouancé ou la constitution d'une ville castrale en Bretagne et Anjou

Figure 16 - Plan des données archéologiques de Pouancé en 2011 (J.-C. Meuret)

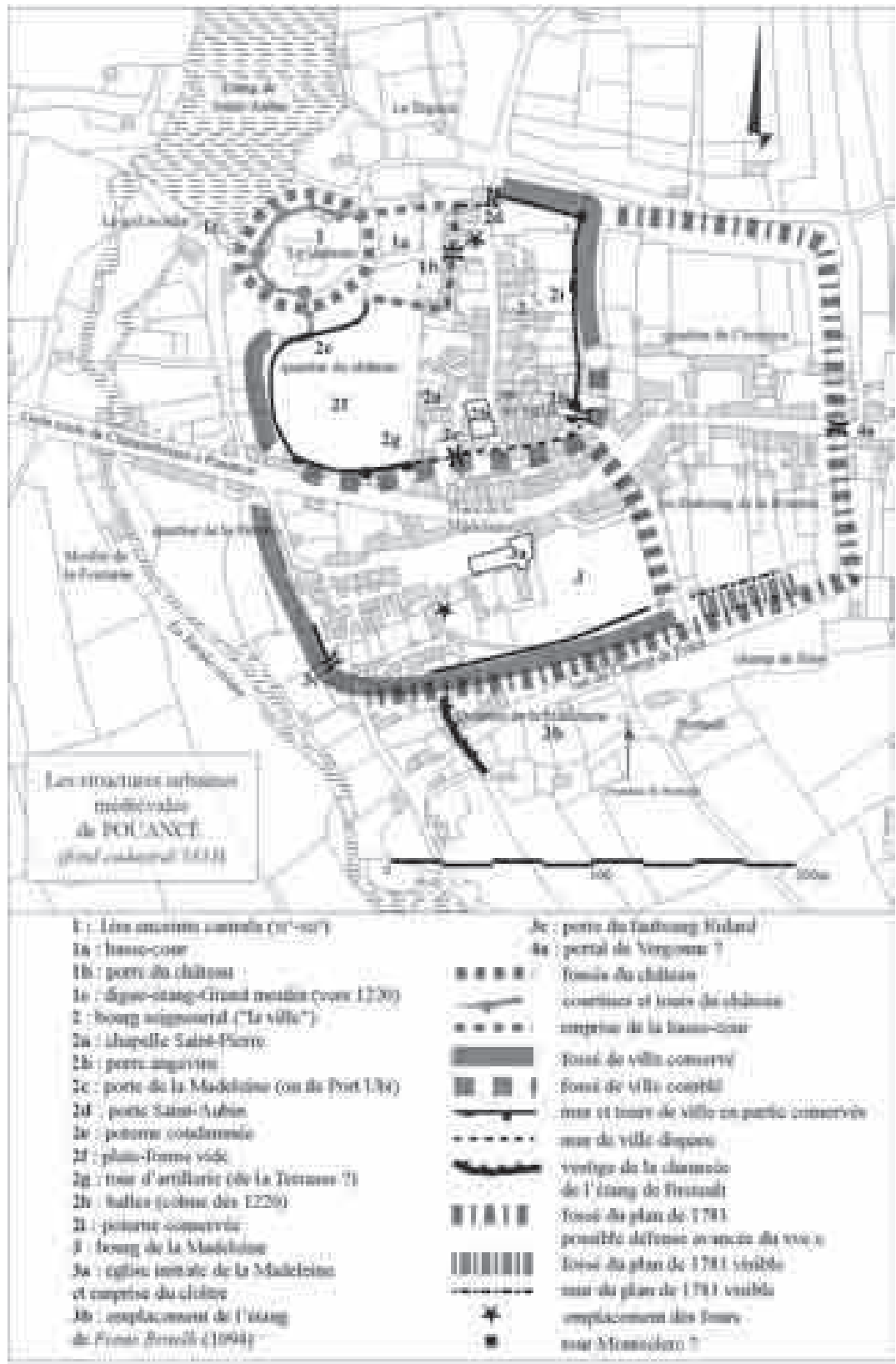


et au système féodal. Il apparaît ainsi que, comme ailleurs, l'évolution de la ville consiste d'abord en une dynamique interne propre, inscrite dans la longue durée. Celle d'un être vivant autonome, complexe, en constante transformation, et dont les différentes fonctions interagissent en permanence : l'étang de Bretault en est un exemple avec une origine lointaine et ignorée, une donation ponctuelle en 1096 à Marmoutier, puis un abandon progressif, sans doute après la création du grand étang, un comblement naturel d'abord, puis accéléré par apport de décombres au XIX siècle, l'extension du champ de foire et les constructions sur son emprise, et aujourd'hui pour tous vestiges, un nom, une fontaine et le léger bourrelet de sa chaussée à peine perceptible. L'évolution de la voirie, des portes et issues n'aurait pu non plus se comprendre autrement que dans un long processus intimement lié à la vie propre de la ville. Il en a encore été de même pour le bourg de la Madeleine. Grâce à une soigneuse recherche de terrain, doublée de ce qu'on peut appeler une archéologie des sources écrites, il a été possible de montrer l'importance majeure de ce bourg, et - au travers de ses murs, fossés, porte(s) - sa pleine inscription dans le long processus urbain. Il en va de même pour les transformations profondes qu'on a pu observer et soupçonner au Xve siècle avec le creusement des grands fossés et l'énorme aménagement de la plate-forme du château - l'un et l'autre sans doute parallèles aux transformations du château - qui résultent sans doute moins d'une hypothétique décision seigneuriale ou royale bien datée, que d'un faisceau et d'une suite de causes et d'évolutions : position en marche de la place de Pouancé, Guerre de Succession de Bretagne, développement progressif de l'artillerie, succession de sièges $\mathrm{au} \mathrm{Xv}^{\mathrm{e}}$ siècle, montée en puissance de la monarchie française et processus d'annexion de la Bretagne. 